\title{
Advances in Analysis of Biodistribution of Exosomes by Molecular Imaging
}

\author{
Yong Weon Yi ${ }^{1}{ }^{1}$, Jun Ho Lee ${ }^{1}$, Sang-Yeob Kim ${ }^{2,3}$, Chan-Gi Pack ${ }^{2,3}{ }^{\mathbb{D}}$, Dae Hyun Ha ${ }^{1}$, \\ Sang Rae Park ${ }^{1}$, Jinkwon Youn ${ }^{1}$ and Byong Seung Cho ${ }^{1, *}$ \\ 1 ExoCoBio Exosome Institute (EEI), ExoCoBio Inc., Seoul 08594, Korea; yongweon.yi@exocobio.com (Y.W.Y.); \\ junho.lee@exocobio.com (J.H.L.); dh.ha@exocobio.com (D.H.H.); sangrae.park@exocobio.com (S.R.P.); \\ jinkwon.youn@exocobio.com (J.Y.) \\ 2 Department of Convergence Medicine, University of Ulsan College of Medicine and Asan Medical Center, \\ Seoul 05505, Korea; sykim3yk@amc.seoul.kr (S.-Y.K.); changipack@amc.seoul.kr (C.-G.P.) \\ 3 Asan Institute for Life Sciences, Asan Medical Center, Seoul 05505, Korea \\ * Correspondence: ceo@exocobio.com; Tel.: +82-2-2038-3915
}

Received: 20 December 2019; Accepted: 16 January 2020; Published: 19 January 2020

check for updates

\begin{abstract}
Exosomes are nano-sized membranous vesicles produced by nearly all types of cells. Since exosome-like vesicles are produced in an evolutionarily conserved manner for information and function transfer from the originating cells to recipient cells, an increasing number of studies have focused on their application as therapeutic agents, drug delivery vehicles, and diagnostic targets. Analysis of the in vivo distribution of exosomes is a prerequisite for the development of exosome-based therapeutics and drug delivery vehicles with accurate prediction of therapeutic dose and potential side effects. Various attempts to evaluate the biodistribution of exosomes obtained from different sources have been reported. In this review, we examined the current trends and the advantages and disadvantages of the methods used to determine the biodistribution of exosomes by molecular imaging. We also reviewed 29 publications to compare the methods employed to isolate, analyze, and label exosomes as well as to determine the biodistribution of labeled exosomes.
\end{abstract}

Keywords: biodistribution; exosomes; labeling; molecular imaging; therapeutics

\section{Introduction}

According to studies conducted over the last half century, nearly all cells on earth produce exosomes or exosome-like particles consisting of a lipid bilayer membrane [1]. The shedding of exosomes is an evolutionarily well-conserved phenomenon found in all biological kingdoms [1]. The discovery of exosomes occurred in the 1940s and platelet-derived particles in normal plasma were first reported in 1946 [2] followed by a re-description as platelet dust in 1967 [3]. However, exosomes received little attention for several decades because they were regarded as cellular garbage bins [4]. In the mid-2000s, important discoveries regarding exosomes changed this trend. In 2007, the transfer of genetic materials such as mRNAs and miRNAs in exosomes was reported [5]. Research on exosomes has been increased explosively since then, with more than 3000 papers published annually in 2018 and 2019 (Figure 1) [1,2,4-22]. Exosomes, ranging 100-200 nm, from stem cells were reported to mediate the paracrine therapeutic effects of stem cells [6]. Exosomes are important mediators of signal transfer in both multicellular and unicellular organisms. They are also important signaling mediators across species [14,23]. In addition to basic research, medical and healthcare industrial applications of exosomes for the development of therapeutics, drug delivery vehicles, and liquid biopsies are rapidly progressing [24-26]. 


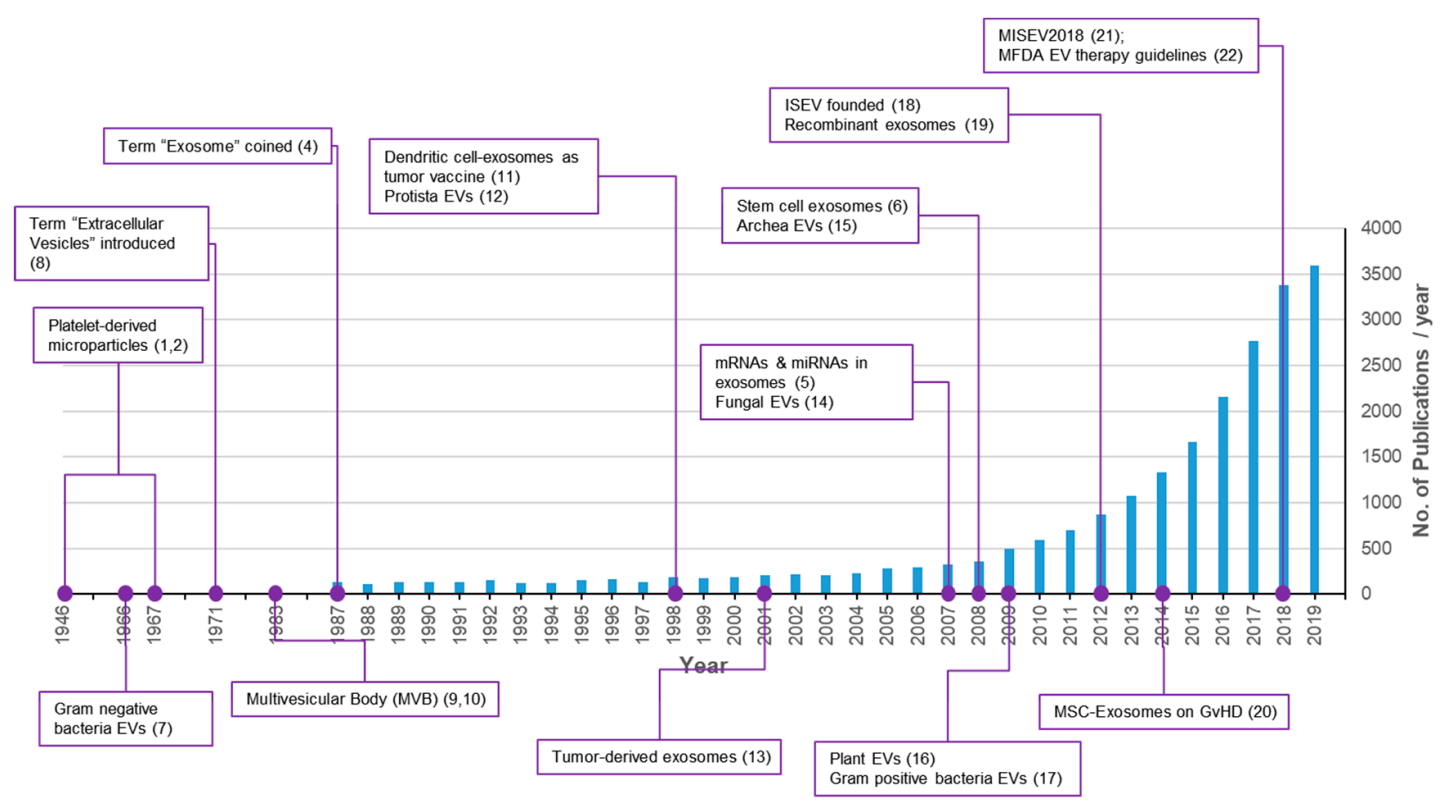

Figure 1. Trends of publications and major discoveries regarding exosomes. The number of publications was retrieved with a PubMed search using the keywords exosomes, exosome, extracellular vesicles, extracellular vesicle, and platelet-derived particles on 17 October 2019.

\section{Exosomes}

\subsection{Exosomes and Extracellular Vesicles}

Extracellular vesicles (EVs) are lipid bilayered vesicles shed by cells. Three major types of EVs have been characterized according to their biogenesis: (1) exosomes are produced through the most complex process; specifically, inward budding of the cellular membrane results in the formation of early endosomes. Another inward budding of the early endosomal membrane results in multivesicular bodies (MVBs). Finally, fusion of MVBs with the plasma membrane sheds exosomes toward the extracellular space. The diameter of exosomes ranges from 30 to $200 \mathrm{~nm}$; (2) microvesicles are produced from simple outward budding of the plasma membrane. The size of microvesicles are known to be from 100 or 200 to $1000 \mathrm{~nm}$; and (3) apoptotic bodies are produced as a result of apoptotic cell death [27]. The apoptotic bodies are the largest type of EVs with size from 500 to $2000 \mathrm{~nm}$ in diameter.

Since apoptotic bodies are byproducts of cell death, numerous attempts to develop EV-based therapeutics have focused on exosomes and microvesicles. Especially, exosomes are widely accepted as next generation therapeutics due to the extensive investigation of potential applications $[28,29]$. As mentioned, the size ranges of exosomes and microvesicles overlap and it is difficult to differentially isolate these EVs according to their size [30-32]. Recently, an alternative term, small extracellular vesicles (sEVs), was proposed to refer to EVs with diameters smaller than $200 \mathrm{~nm}$ [21]. In this review, we refer to these smaller EVs as exosomes.

Specific markers of exosomes have been reported: ALIX and TSG101 are well-established markers of exosomes, and tetraspanins such as CD9, CD63, and CD81 are specific markers on the exosomal membrane. Additionally, exosomes contain a variety of specific proteins depending on their cells of origin [31]. Interestingly, it has been reported that exosomes derived from mesenchymal stem cells (MSCs) or HEK 293T cells do not contain class I and class II human major histocompatibility complex (MHC) proteins or co-stimulatory molecules such as CD80 and CD86. The absence of these proteins on the exosomal surface suggests no immune rejection can be expected for allogeneic therapeutics [32-35]. Exosomes derived from stem cells are actively being developed as a cell-free therapy because they recapitulate the functions of stem cells such as repair, regeneration, anti-inflation, and immune modulation without the limitations and risks of stem cells themselves [30,31,36,37]. As an example, exosomes derived from MSCs have therapeutic effects on various diseases including 
myocardial infarction [6,38], CCl4-induced liver injury [39], graft-versus-host disease (GvHD) [20], acute and chronic kidney injury [40], and atopic dermatitis [34,41].

The size of exosomes enables their safe systemic administration through multiple routes without the risk of embolism compared to cell-based therapy [42]. There is also a low risk of tumorigenesis since exosomes cannot replicate themselves [43]. In addition, the use of exosomes would avoid various issues related to cell therapy such as the inability to sterilize the cells, short shelf-life, and limited quality control $(\mathrm{QC})$ before release $[41,44]$. A couple of studies have also reported that exosomes from MSCs and HEK 293T did not cause toxicity in vivo or in vitro [44-48]. A recent study suggested that long-term repetitive injection of exosomes does not induce toxicity [45]. Nano-sized exosomes may reach and accumulate in additional tissues beyond the tissues of therapeutic interest through systemic administration. Therefore, analysis of the biodistribution following administration through the intended route is a prerequisite for the development of exosome-based therapeutics.

\subsection{Technologies for Isolation of Exosomes}

The most important hurdle to overcome for exosome-based therapy is development of the proper technologies for large scale isolation of exosomes [49]. Exosomes from different sources have been isolated with various experimental methods such as differential ultracentrifugation (UC), density gradient ultracentrifugation (DGUC), ultrafiltration (UF), size exclusion chromatography (SEC), precipitation, and tangential flow filtration (TFF) [50,51]. According to a recent report, UC is the most widely used method to isolate exosomes from conditioned media of MSCs [24]. Commercial kits, which are mostly based on the precipitation of proteins, were the second choice for exosome isolation among the 126 papers analyzed in a recent report [24].

Among various methods, TFF has been proposed as the ideal method for industrial manufacture of exosomes [51]. Compared to other methods, which have limited compliance with good manufacturing practice (GMP), the availability of GMP-compliant TFF systems may also result in validated process control and GMP documents [50]. Methods based on UC have a risk of producing exosomes with co-precipitated contaminants and functional loss due to exosome aggregation caused by high pressure during centrifugation. The media used in DGUC may inhibit the function of exosomes [51]. Commercial kits based on protein precipitation are widely used in many academic labs. However, the additives used for precipitation (e.g., polyethylene glycol (PEG)) may inhibit the biological functions of exosomes. Although SEC has the advantage of removing proteins smaller than exosomes, a low recovery rate and the potential loss of exosome function were reported [51]. In principle, SEC cannot distinguish exosomes from non-exosomal particles with similar sizes. Recent reports revealed the functional importance of proteins associated with the surface of exosomes [52,53]. These results suggest that careful selection of the proper methods is important to isolate functional exosomes without the loss of these surface-associated proteins.

\subsection{Quality Control of Exosomes}

The QC of isolated exosomes is of importance for both reproducible research and the development of therapeutics. In an international effort to establish standards for exosome analysis, the Minimal Information for Studies of Extracellular Vesicles 2018 (MISEV 2018) was suggested through a series of publications $[21,54,55]$. Many studies also reported on the GMP production of exosomes for the development of therapeutics with suggested release criteria [45,50,56-61]. The worldwide market for exosome-based therapy is expected to grow from 5 million USD in 2016 to 10.0 million USD in 2021, with a compound annual growth rate (CAGR) of $14.9 \%$ [62]. In terms of regulation, fast-track approval of exosome therapeutics by regulatory authorities in Korea, Italy, and China is expected [62]. The Korea Ministry of Food and Drug Safety (MFDS) published the Guideline on Quality, Non-clinical and Clinical Assessment of Extracellular Vesicles Therapy Products in 2018 [22]. As shown in Table 1, most of the criteria in the MISEV 2018 and the MFDS Guideline are quite similar. The MFDS Guideline also includes guides for the characterization of starting materials, methods for the production, isolation, and 
characterization of exosomes, stability testing, the consideration of non-clinical studies, toxicological evaluation, and the considerations of clinical studies.

Table 1. Comparison of Minimal Information for Studies of Extracellular Vesicles 2018 (MISEV2018) and the Korea Ministry of Food and Drug Safety (MFDS) Guideline.

\begin{tabular}{|c|c|c|c|}
\hline QC Criteria & MISEV2018 Recommendation & MFDS Guideline (2018) & Examples \\
\hline Exosome Size & RPS, NTA, DLS, etc. & $\begin{array}{l}\text { NTA, DLS, RPS, fluorescence } \\
\text { correlation spectroscopy, etc. }\end{array}$ & NTA \\
\hline Purity & $\begin{array}{c}\text { Ratios of two quantification } \\
\text { figures (e.g., protein:particle) } \\
\text { Assessment of absence of expected } \\
\text { contamination }\end{array}$ & $\begin{array}{l}\text { For proteins which are not } \\
\text { expected to enrich in } \\
\text { exosomes; } \\
\text { For process impurities: serum } \\
\text { albumin, antibiotics, etc. }\end{array}$ & $\begin{array}{l}\text { ELISA for Calnexin or GM130 } \\
\text { ELISA for impurities }\end{array}$ \\
\hline Others & not mentioned & $\begin{array}{c}\text { Mycoplasma, Sterility, } \\
\text { Endotoxin, and Virus tests }\end{array}$ & \\
\hline
\end{tabular}

\section{Analysis of Exosomes Biodistribution}

\subsection{Bioimaging Modalities}

Various modalities, such as bioluminescence imaging (BLI), nuclear, fluorescence, and magnetic resonance imaging (MRI) [63-65], have been used for in vivo imaging (Table 2). In general, BLI is known to have the highest sensitivity and high signal-to-noise ratio while nuclear imaging has the highest penetration [63]. However, BLI with luciferase requires additional administration of substrates for luciferase and is limited by the low spatial and temporal resolution. Nuclear imaging requires hazardous radioisotopes with low spatial resolution and high cost. Fluorescence imaging with near infrared (NIR) fluorescent dyes is limited by the spatial and temporal resolution. Fluorescence imaging using fluorescent proteins (FP) has the highest spatial resolution. However, the low penetration of FP fluorescence does not allow noninvasive in vivo imaging. MRI has high penetration with high spatial and temporal resolution but is limited by low sensitivity and high cost.

Table 2. Comparison of bioimaging modalities.

\begin{tabular}{|c|c|c|c|}
\hline Modality & Examples & Pros & Cons \\
\hline $\begin{array}{l}\text { Bioluminescence } \\
\text { Imaging }[63,64]\end{array}$ & Luciferase & $\begin{array}{c}\text { Highest sensitivity }\left(10^{-15}-10^{-17} \text { mole/L) }\right. \\
\text { Medium cost } \\
\text { High signal-to-noise (compared to } \\
\text { fluorescence) }\end{array}$ & $\begin{array}{l}\text { Substrate needed } \\
\text { Medium penetration }(\mathrm{mm}-\mathrm{cm}) \\
\text { Low spatial resolution }(\mathrm{mm}) \\
\text { Low temporal resolution }(\mathrm{sec}-\mathrm{min})\end{array}$ \\
\hline $\begin{array}{l}\text { Nuclear Imaging } \\
\text { (PET/SPECT) [63-65] }\end{array}$ & $99 \mathrm{mTc}$ & $\begin{array}{l}\text { Highest penetration }(\mathrm{m}) \\
\text { High sensitivity }\left(10^{-10}-10^{-12} \mathrm{~mole} / \mathrm{L}\right) \\
\text { Medium temporal resolution }(10 \mathrm{~s}-\mathrm{min})\end{array}$ & $\begin{array}{c}\text { Hazardous } \\
\text { Low spatial resolution }(\mathrm{mm}) \\
\text { High cost }\end{array}$ \\
\hline $\begin{array}{l}\text { NIR Fluorescence } \\
\text { Imaging }[63,64]\end{array}$ & DiR & $\begin{array}{c}\text { Medium penetration }(\mathrm{mm}-\mathrm{cm}) \\
\text { Medium sensitivity }\left(10^{-9}-10^{-12} \text { mole/L) }\right. \\
\text { Low cost }\end{array}$ & $\begin{array}{l}\text { Low spatial resolution }(\mathrm{mm}) \\
\text { Low temporal resolution }(\mathrm{s}-\mathrm{min})\end{array}$ \\
\hline $\begin{array}{l}\text { Fluorescent Protein } \\
\text { Imaging }[63,64]\end{array}$ & GFP & $\begin{array}{l}\text { Highest spatial resolution }(\mathrm{nm}) \\
\text { Medium sensitivity }\end{array}$ & $\begin{array}{l}\text { Lowest penetration }(\mathrm{mm}) \text { : does not } \\
\text { allow noninvasive in vivo imaging }\end{array}$ \\
\hline
\end{tabular}




\subsection{Labeling Methods for Exosomes}

For in vivo imaging, exosomes have to be labeled with probes using proper methods. Methods for labeling probes include covalent binding, genetic modification, membrane integration, encapsulation (or internalization), and metabolic labeling (Table 3).

\subsubsection{Covalent Binding}

Covalent binding can be used to label exosomes by reacting them with probes that have functional moieties. Due to the covalent bonding, labeled probes tightly bind to exosomes with minimal dissociation. However, nonspecific exosomal proteins may also be labeled when using this method. Additionally, the labeling of exosomal surface proteins may affect their function and/or structure resulting in altered interactions of the exosomes with the target cells. It was recently reported that the modification of surface proteins altered the biodistribution of exosomes [66]. According to this report, treatment of glycosidase with exosomes resulted in a slight increase in the lung distribution of exosomes in mice compared to the distribution of untreated exosomes. However, it is necessary to further explore this finding with a large number of animals to obtain more statistically significant results since only three mice per group were used in the study. Another study performed without covalent binding suggested that labeling exosomes with lipophilic dyes also slightly changes the biodistribution of exosomes. The researchers labeled exosomes containing luciferase, with a lipophilic fluorescent dye and compared the biodistribution of the exosomes with and without the lipophilic dyes [67]. The exosomes without the lipophilic dye, accumulated in the organs in the following order: lung $>$ liver $>$ spleen $>$ kidney. On the contrary, the exosomes with the lipophilic dye accumulated in the organs in the following order: liver > lung and spleen. Taken together, it is necessary to develop a method to analyze the effect of exosome surface modification.

\subsubsection{Surface Modification}

Surface modification of exosomes can be avoided by genetic modification to load probe proteins into exosomes. To date, luciferase proteins are mostly used for genetic modification (Table 4). However, genetic modification may change the property of cells and even exosomes. Uneven loading of probe proteins is another issue that needs to be addressed $[68,69]$.

\subsubsection{Membrane Integration}

The most widely used labeling method for exosomes is membrane integration of lipophilic fluorescent dyes. This method is simple and easy, but carries the risk of exosome aggregation [65]. Another issue with lipophilic dyes is that they can label both lipoproteins and lipid micelles. Lipophilic dyes have been widely used to analyze the biodistribution of cells for the development of cell-based therapies. A study reported that there was no transfer of lipophilic dyes such as PKH67 or Dil from labeled to unlabeled cells in co-culture conditions [70]. These results suggest that there is a low risk of background signals resulting from the transfer of lipophilic dyes released from exosome membranes to the target tissue or cells. On the other hand, the long in vivo half-life of lipophilic dyes may cause pseudo signals after the clearance of exosomes [65]. The in vivo half-life of PKH2 and PKH26 was reported to be 12 days and more than 100 days, respectively [71]. Dialkylcarbocyanine dyes, such as $\mathrm{DiD}, \mathrm{Dil}, \mathrm{DiO}$, and DiR, are also widely used. The in vivo half-life of $\mathrm{DiR}$ is known to be approximately 4 weeks [72]. Taken together, it is necessary to include a control containing lipophilic dyes alone [45]. Another potential issue with the use of lipophilic dyes is the formation of micelles in the liquid because of the lipophilic nature of the dyes [73]. When PKH26 or CM-Dil was incubated in phosphate-buffered saline (PBS) without exosomes, there were detectable levels of particles. On the contrary, in our studies, no detectable particles were observed when PKH dyes were incubated in the PBS without exosomes. In addition, no detectable changes in particle numbers were observed when PKH dyes were reacted with exosomes at the appropriate concentration (unpublished observation). Again, it is important to 
include a negative control that consists of the lipophilic dyes in the same buffer without exosomes. Since removal of free unlabeled dyes is a prerequisite, it is also important to process this negative control using with same removal method.

\subsubsection{Encapsulation}

Encapsulation can be applied to label exosomes, while avoiding surface modification. However, electroporation may cause the aggregation of exosomes or structural distortion of the membrane, resulting in fused exosomes [65]. When lipophilic materials are used for encapsulation, it is difficult to exclude the possibility of sustained release of internalized probes from the exosomes. It is expected that uneven distribution of transporter proteins on the exosome membrane may cause uneven loading of probes when a transporter protein is utilized for the encapsulation of probes. The expression of a specific transporter protein is also limited by the cell types.

\subsubsection{Metabolic Labeling}

Metabolic labeling of exosomes is achievable with the addition of specific substances during the cell culture process. After the isolation of metabolically labeled exosomes, covalent binding of the probes can be achieved with click chemistry [74]. However, the addition of extra substances during cell culture may cause changes in the characteristics of the cells or exosomes.

\subsection{Analysis of Biodistribution of Exosomes in Literature}

We analyzed 29 published papers that reported biodistribution studies of different exosomes or EVs (Table 4). The most widely used labeling method was membrane integration of lipophilic dyes followed by covalent binding, encapsulation (or internalization), and genetic engineering (Figure 2). Only one paper described metabolic labeling.
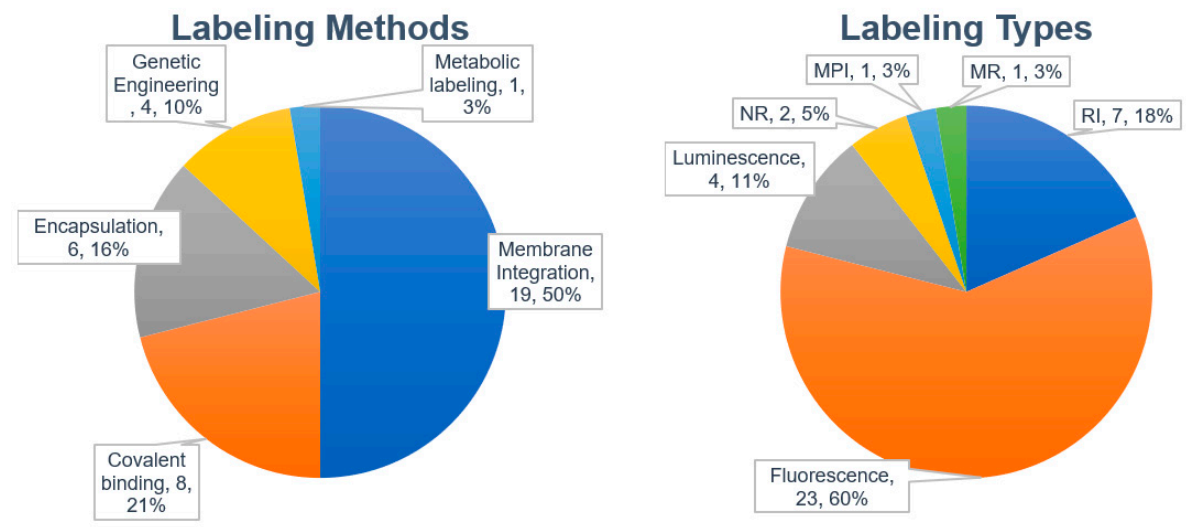

Figure 2. Labeling methods and probes used for labeling exosomes.

\subsubsection{Labeling Methods}

All four papers involving genetic engineering described the use of luciferases. No publication was reported using fluorescent proteins (Table 4). As discussed, the low penetration of fluorescence is not suitable for noninvasive in vivo imaging (Table 2). Genetic engineering may cause changes in the characteristics of host cells or even exosomes. When genetically modified cells are used to produce labeled exosomes, the possibility of differences in the characteristics of labeled exosomes for biodistribution analysis and unlabeled exosomes for therapeutic use cannot be excluded. On the other hand, genetically labeled exosomes have an advantage in comparing their in vivo distribution with and without additional labeling. Especially, genetically labeled exosomes can be utilized to monitor the effects of surface modifications, such as covalent binding or membrane integration, which may cause structural or functional changes in the membranes of exosomes [67]. 
Table 3. Comparison of labeling methods.

\begin{tabular}{|c|c|c|c|}
\hline Labeling Methods & Pros & Cons & Reference \\
\hline Covalent biding & $\begin{array}{l}\text { Tight binding of probes } \\
\text { to proteins }\end{array}$ & $\begin{array}{l}\text { Cannot distinguish between exosomes vs. } \\
\text { non-exosome proteins } \\
\text { May change membrane protein functions } \\
\text { which affect the interaction of exosomes } \\
\text { with target cells }\end{array}$ & [66] \\
\hline Genetic modification & $\begin{array}{l}\text { Can avoid surface } \\
\text { modification }\end{array}$ & $\begin{array}{l}\text { Genetic change of cells may change the } \\
\text { property of cells and/or exosomes } \\
\text { Uneven loading into exosomes }\end{array}$ & [68] \\
\hline $\begin{array}{c}\text { Membrane integration } \\
\text { (lipophilic fluorescent } \\
\text { dyes) }\end{array}$ & Simple and easy & $\begin{array}{c}\text { May cause clumping of exosomes } \\
\text { Cannot distinguish between lipid proteins } \\
\text { and micelle } \\
\text { May cause background signals from } \\
\text { dissociated probes } \\
\text { May cause pseudo signals even after } \\
\text { clearance of exosomes } \\
\text { May affect the interaction of exosomes with } \\
\text { target cells }\end{array}$ & [65] \\
\hline $\begin{array}{l}\text { Encapsulation by } \\
\text { electroporation }\end{array}$ & $\begin{array}{l}\text { May avoid surface } \\
\text { modification }\end{array}$ & $\begin{array}{l}\text { May cause aggregation or fusion of } \\
\text { exosomes }\end{array}$ & {$[65]$} \\
\hline $\begin{array}{l}\text { Encapsulation by } \\
\text { lipophilic agents }\end{array}$ & Simple and easy & $\begin{array}{l}\text { May cause background signals from } \\
\text { released probes }\end{array}$ & [65] \\
\hline $\begin{array}{l}\text { Transporter-dependent } \\
\text { encapsulation }\end{array}$ & Simple and easy & $\begin{array}{l}\text { Depends on transporter (e.g., GLUT1) } \\
\text { Un-even encapsulation } \\
\text { May cause background signals from } \\
\text { released probes }\end{array}$ & [75] \\
\hline Metabolic labeling & $\begin{array}{l}\text { Covalent biding of } \\
\text { probes by click chemistry }\end{array}$ & $\begin{array}{l}\text { May change the property of cells and/or } \\
\text { exosomes } \\
\text { May change membrane protein functions } \\
\text { which affect the interaction of exosomes } \\
\text { with target cells }\end{array}$ & {$[74,76]$} \\
\hline
\end{tabular}

Labeling of exosomes by encapsulation has been performed with various labeling probes such as radioisotopes, nanoparticles, and fluorescent dyes (Table 4). Passive loading of probes is frequently used. An interesting example of active loading of probes is the use of transporter proteins on the membrane of exosomes. A study reported the encapsulation of glucose-coated gold nanoparticles by the GLUT1 glucose transporter on the exosomal membrane [75]. Additional transporters are expected to be available for the specific encapsulation of probes in exosomes obtained from different sources with the advancement of research. However, the distribution or abundance of transporter proteins on the exosomal membrane may cause the uneven loading of proteins. Sonication was also employed to encapsulate probes in exosomes [76]. However, sonication may cause distortion or damage to the exosomal membrane, eventually affecting the biodistribution of exosomes. Additionally, superparamagnetic iron oxide (SPIO) nanoparticles have been used to label exosomes through the transfection of exosome-producing cells [75]. It is important to recognize that the loading amount of nanoparticles is restricted by their size. The hydrodynamic radius of SPIO nanoparticles in a previous report [75] was $62 \mathrm{~nm}$ (https://www.magneticinsight.com/wp-content/uploads/2016/05/VivoTrax datasheet.pdf). Since the diameter of exosomes in the study is around $100 \mathrm{~nm}$ [75], the loading efficiency of SPIO nanoparticles in exosomes seems to be limited. 
Table 4. Biodistribution of exosomes in literature.

\begin{tabular}{|c|c|c|c|c|c|c|c|c|c|c|c|}
\hline $\begin{array}{l}\text { Labeling } \\
\text { Method }\end{array}$ & Modality & $\begin{array}{c}\text { Nomenclature } \\
\text { (Markers) }\end{array}$ & Cell Source & Isolation Method & $\begin{array}{l}\text { Purification } \\
\text { after Labeling }\end{array}$ & $\begin{array}{c}\text { Dose } \\
\text { (/Head) }\end{array}$ & Animal Model & $\begin{array}{l}\text { Admin. } \\
\text { Route }\end{array}$ & $\begin{array}{l}\text { Imaging } \\
\text { Method }\end{array}$ & Tissue Distribution & Ref. \\
\hline $\begin{array}{l}\text { Covalent } \\
\text { binding }\end{array}$ & $\begin{array}{c}\mathrm{RI} \\
\left({ }^{124 I}\right)\end{array}$ & EVs & $\begin{array}{c}\text { MLP29 } \\
\text { (murine } \\
\text { liver-derived } \\
\text { progenitor cell } \\
\text { line) }\end{array}$ & $\begin{array}{c}\mathrm{UC} \\
(100,000 \mathrm{~g}, 70 \mathrm{~min})\end{array}$ & $\begin{array}{c}\text { SEC } \\
\text { (Sephadex } \\
\text { G-25) }\end{array}$ & $\begin{array}{c}0.6-1.8 \\
\text { MBq } \\
(40-120 \mathrm{ng})\end{array}$ & $\begin{array}{c}\text { Mouse } \\
\text { (BALB/cJRj) }\end{array}$ & $\begin{array}{l}\text { IV } \\
\text { hock }\end{array}$ & PET & $\begin{array}{l}\text { Bladder }>\text { liver }>\text { thyroid } \\
>\text { lung }>\text { kidney }>\text { brain }\end{array}$ & [66] \\
\hline $\begin{array}{l}\text { Covalent } \\
\text { binding }\end{array}$ & $\begin{array}{l}\text { Fluorescence } \\
\text { (Cy7-NHS) }\end{array}$ & $\begin{array}{l}\text { Exosomes } \\
\text { (CD9, ALIX, } \\
\text { TSG101) }\end{array}$ & $\begin{array}{l}\text { Human U937 } \\
\text { leukemia cells }\end{array}$ & $\begin{array}{c}\mathrm{UC} \\
(100,000 \mathrm{~g}, 2 \mathrm{~h})\end{array}$ & $\begin{array}{c}\text { SEC } \\
\text { (Sephadex } \\
\text { G50) }\end{array}$ & $40 \mu \mathrm{g}$ & $\begin{array}{c}\text { Mouse } \\
\text { (BALB/c) with } \\
\text { syngeneic CT26 } \\
\text { colon } \\
\text { adenocarcinoma }\end{array}$ & IV & IVIS & $\begin{array}{l}\text { Liver > kidney, tumor, } \\
\text { spleen, heart, lung, colon, } \\
\text { brain, bladder, blood }\end{array}$ & [77] \\
\hline $\begin{array}{l}\text { Covalent } \\
\text { binding }\end{array}$ & $\begin{array}{l}\text { Fluorescence } \\
\text { (Cy7-NHS) }\end{array}$ & EVs & Helicobacter pylori & $\begin{array}{c}\mathrm{UC}(150,000 \mathrm{~g}, 3 \mathrm{~h}) \\
\text { and DGUC } \\
(100,000 \mathrm{~g}, 2 \mathrm{~h})\end{array}$ & Not disclosed & $\begin{array}{c}\text { Not } \\
\text { disclosed }\end{array}$ & $\begin{array}{c}\text { Mouse } \\
\text { (C57BL/6) }\end{array}$ & Oral & IVIS & Mouse, stomach & [78] \\
\hline $\begin{array}{l}\text { Covalent } \\
\text { binding }\end{array}$ & $\begin{array}{l}\text { Fluorescence } \\
\text { (Cy7-NHS) }\end{array}$ & $\begin{array}{l}\text { Bacterial EVs } \\
\text { (OMVs) }\end{array}$ & E. coli & $\begin{array}{c}\mathrm{UC} \\
(150,000 \mathrm{~g}, 3 \mathrm{~h})\end{array}$ & $\begin{array}{c}\text { UC } \\
(150,000 \mathrm{~g}, 3 \mathrm{~h})\end{array}$ & $15 \mu \mathrm{g}$ & $\begin{array}{c}\text { Mouse } \\
\text { (C57BL/6 and } \\
\text { SKH1-E) }\end{array}$ & IP & IVIS & $\begin{array}{c}\text { (3 h) liver }>\text { kidney }>\text { lung } \\
>\text { spleen }>\text { small intestine } \\
(24 \mathrm{~h}) \text { liver }\end{array}$ & [79] \\
\hline $\begin{array}{l}\text { Covalent } \\
\text { binding }\end{array}$ & $\begin{array}{c}\text { RI } \\
\left({ }^{111} \text { Indium }\right)\end{array}$ & $\begin{array}{l}\text { Exosomes } \\
\text { (CD81, CD9) }\end{array}$ & $\begin{array}{l}\text { Murine B16F10 } \\
\text { melanoma }\end{array}$ & $\begin{array}{c}\mathrm{UC} \\
(100,000 \mathrm{~g}, 90 \mathrm{~min})\end{array}$ & $\begin{array}{c}\text { SEC } \\
\text { (Sepharose } \\
\text { CL-2B) }\end{array}$ & $1 \times 10^{11}$ & $\begin{array}{c}\text { Mouse } \\
\text { (C57BL/6 and NSG), } \\
\text { melanoma-bearing }\end{array}$ & IV & SPECT/CT & $\begin{array}{l}\text { Liver }>\text { spleen }>\text { bone, } \\
\text { kidney, lung }\end{array}$ & [80] \\
\hline $\begin{array}{l}\text { Covalent } \\
\text { binding }\end{array}$ & $\begin{array}{c}\mathrm{RI} \\
\left({ }^{131} \mathrm{I}\right)\end{array}$ & $\begin{array}{l}\text { Exosomes } \\
\text { (CD9, CD63) }\end{array}$ & $\begin{array}{c}\text { Mouse MDSCs } \\
\text { and EPCs, HEK293 }\end{array}$ & $\begin{array}{c}\mathrm{UF}(100 \mathrm{kDa}) \\
\text { and UC } \\
(100,000 \mathrm{~g}, 70 \mathrm{~min})\end{array}$ & $\begin{array}{c}\text { UF } \\
(100 \mathrm{kDa})\end{array}$ & $\begin{array}{c}350 \pm 50 \\
\mu \mathrm{Ci}\end{array}$ & $\begin{array}{c}\text { Mouse } \\
\text { (BALB/c or } \\
\text { C57BL/J6) } \\
\text { Xenograft bearing } \\
4 \mathrm{~T} 1 \text { or AT3 }\end{array}$ & IV & SPECT/CT & $\begin{array}{l}\text { (Tumor exosomes) tumor } \\
>\text { liver }>\text { lung, spleen, } \\
\text { kidney, brain, heart } \\
\text { (MDSC-exosome) liver, } \\
\text { lung, tumor > kidney, } \\
\text { spleen, brain, heart } \\
\text { (EPC-exosomes) tumor > } \\
\text { liver }>\text { lung, kidney, brain, } \\
\text { spleen, heart }\end{array}$ & [81] \\
\hline $\begin{array}{l}\text { Covalent } \\
\text { binding }\end{array}$ & $\begin{array}{c}\mathrm{RI} \\
\begin{array}{c}{ }^{99 \mathrm{~m}} \mathrm{Tc}(\mathrm{CO})_{3} \\
\left.\left(-\mathrm{H}_{2} \mathrm{O}\right)_{3}\right]^{+}\end{array} \\
\end{array}$ & EVs & Erythrocyte & $\begin{array}{c}\mathrm{UC} \\
(130,000 \mathrm{~g}, 30 \mathrm{~min}) \\
\text { and SEC }\end{array}$ & $\begin{array}{c}\text { SEC } \\
\text { (Desalting } \\
\text { Column) } \\
\end{array}$ & $15 \pm 2 \mathrm{Mbq}$ & $\begin{array}{l}\text { Mouse } \\
(\mathrm{BALB} / \mathrm{c})\end{array}$ & IV & SPECT/CT & $\begin{array}{l}\text { Liver, bladder, spleen }> \\
\text { kidney }>\text { lung, heart, bone }\end{array}$ & [82] \\
\hline $\begin{array}{l}\text { Metabolic } \\
\text { labeling }\end{array}$ & $\begin{array}{l}\text { Fluorescence } \\
\text { (Cy3 or } \\
\text { Cy5.5) }\end{array}$ & $\begin{array}{l}\text { Exosomes } \\
\text { (CD63) }\end{array}$ & $\begin{array}{c}\text { Human } \\
\text { MDA-MD-231 and } \\
\text { MCF7 breast } \\
\text { cancer cells }\end{array}$ & ExoQuick & $\begin{array}{l}\text { Gel filtration } \\
\quad(G-25)\end{array}$ & $10 \mu \mathrm{g}$ & $\begin{array}{l}\text { Mouse, athymic } \\
\text { MDA-MB-231 or } \\
\text { MCF7 tumor bearing }\end{array}$ & IV & IVIS & $\begin{array}{c}\text { (MCF7 exosomes) liver > } \\
\text { large and small intestines } \\
>\text { kidney, tumor, spleen, } \\
\text { lung, muscle, blood } \\
\text { (MDA-MD-231 exosomes) } \\
\text { liver > large and small } \\
\text { intestines > lung > tumor, } \\
\text { spleen, kidney > muscle, } \\
\text { blood }\end{array}$ & [74] \\
\hline
\end{tabular}


Table 4. Cont.

\begin{tabular}{|c|c|c|c|c|c|c|c|c|c|c|c|}
\hline $\begin{array}{l}\text { Labeling } \\
\text { Method }\end{array}$ & Modality & $\begin{array}{l}\text { Nomenclature } \\
\text { (Markers) }\end{array}$ & Cell Source & Isolation Method & $\begin{array}{c}\text { Purification } \\
\text { after Labeling }\end{array}$ & $\begin{array}{c}\text { Dose } \\
\text { (/Head) }\end{array}$ & Animal Model & $\begin{array}{l}\text { Admin. } \\
\text { Route }\end{array}$ & $\begin{array}{l}\text { Imaging } \\
\text { Method }\end{array}$ & Tissue Distribution & Ref. \\
\hline $\begin{array}{l}\text { Genetic } \\
\text { Engineering }\end{array}$ & $\begin{array}{l}\text { Luminescence } \\
\text { (CD63-NanoLuc) }\end{array}$ & $\begin{array}{l}\text { Exosomes } \\
\text { c) }\end{array}$ & $\begin{array}{c}\text { HT29/CD63Nluc } \\
\text { and } \\
\text { HCD116/CD63Nluc }\end{array}$ & $\begin{array}{c}\mathrm{UC} \\
(110,000 \mathrm{~g}, 70 \mathrm{~min})\end{array}$ & NA & NA & $\begin{array}{l}\text { Female mouse } \\
(\text { Balb/c-nu/nu) }\end{array}$ & $\begin{array}{c}\text { NA } \\
\text { (SC } \\
\text { implant of } \\
\text { cells) }\end{array}$ & $\begin{array}{c}\text { BLI } \\
\text { (IVIS) }\end{array}$ & Stomach, intestine & [83] \\
\hline $\begin{array}{c}\text { Genetic } \\
\text { Engineering }\end{array}$ & $\begin{array}{l}\text { Luminescence } \\
\text { (Renilla } \\
\text { Luciferase; } \\
\text { Rluc) }\end{array}$ & $\begin{array}{c}\text { EVs } \\
\text { (CD63, Alix) }\end{array}$ & $\begin{array}{l}\text { CAL-62 thyroid } \\
\text { cancer cell and } \\
\text { MDA-MB-231 } \\
\text { breast cancer cells }\end{array}$ & $\begin{array}{c}\mathrm{UC} \\
(100,000 \mathrm{~g}, 60 \mathrm{~min})\end{array}$ & NA & $25 \mu \mathrm{g}$ & $\begin{array}{c}\text { Mouse } \\
\text { (BALB/c, female) } \\
\mathrm{N}=3\end{array}$ & IV & $\begin{array}{c}\text { BLI } \\
\text { (IVIS) }\end{array}$ & $\begin{array}{c}\text { 62/Rluc: lung }>\text { liver }> \\
\text { spleen }>\text { kidney } \\
\text { 62/Rluc/DiR: liver }>\text { lung, } \\
\text { spleen } \\
\text { 231Rluc: lung, liver }> \\
\text { spleen }>\text { kidney }\end{array}$ & [67] \\
\hline $\begin{array}{c}\text { Genetic } \\
\text { Engineering }\end{array}$ & $\begin{array}{l}\text { Luminescence } \\
\text { (Gaussia } \\
\text { Luciferase) }\end{array}$ & $\begin{array}{c}\text { EVs } \\
(\text { CD63, ALIX) }\end{array}$ & HEK293T cells & $\begin{array}{c}\text { UC } \\
(100,000 \mathrm{~g}, 90 \mathrm{~min})\end{array}$ & $\mathrm{NA}$ & $100 \mu \mathrm{g}$ & $\begin{array}{c}\text { Mouse } \\
\text { (athymic nude) }\end{array}$ & IV & BLI & $\begin{array}{l}\text { Spleen, liver > lung, } \\
\text { kidney, brain, heart, } \\
\text { muscle }\end{array}$ & [84] \\
\hline $\begin{array}{c}\text { Genetic } \\
\text { Engineering }\end{array}$ & $\begin{array}{l}\text { Luminescence } \\
\text { (Gaussia } \\
\text { Luciferase) }\end{array}$ & Exosomes & $\begin{array}{l}\text { B16-B16 murine } \\
\text { melanoma cells }\end{array}$ & $\begin{array}{c}\mathrm{UC} \\
(100,000 \mathrm{~g}, 1 \mathrm{~h})\end{array}$ & NA & $\begin{array}{l}1 \times 10^{10} \\
\mathrm{RLU} \\
(5 \mu \mathrm{g})\end{array}$ & $\begin{array}{c}\text { Mouse } \\
(\mathrm{BALB} / \mathrm{c})\end{array}$ & IV & $\begin{array}{c}\text { BLI } \\
\text { (LAS3000) }\end{array}$ & $\begin{array}{c}\text { Lung }>\text { spleen }>\text { kidney, } \\
\text { liver, heart, brain, } \\
\text { intestine }\end{array}$ & [85] \\
\hline $\begin{array}{l}\text { Membrane } \\
\text { integration }\end{array}$ & $\begin{array}{c}\text { MR } \\
\text { (gadolinium) }\end{array}$ & $\begin{array}{l}\text { Exosomes } \\
\text { (CD9, CD63, } \\
\text { CD81) }\end{array}$ & Human UC-MSCs & $\begin{array}{c}\mathrm{UC} \\
(120,000 \mathrm{~g}, 90 \mathrm{~min})\end{array}$ & $\begin{array}{c}\mathrm{UF} \\
(10 \mathrm{kDa})\end{array}$ & $\begin{array}{c}0.015 \\
\mathrm{mmol} / \mathrm{kg}\end{array}$ & $\begin{array}{l}\text { Mouse, K7M2 } \\
\text { (human } \\
\text { osteosarcoma) } \\
\text { xenograft } \\
\text { (NU/NU) }\end{array}$ & IV & MRI & $\begin{array}{l}\text { Liver, spleen }>\text { tumor }> \\
\text { lung, kidney, heart, brain }\end{array}$ & [86] \\
\hline $\begin{array}{l}\text { Membrane } \\
\text { integration }\end{array}$ & $\begin{array}{l}\text { Fluorescence } \\
\quad \text { (DiR) }\end{array}$ & $\begin{array}{l}\text { Exosomes } \\
\text { (CD9, CD63, } \\
\text { CD81) }\end{array}$ & Human UC-MSCs & $\begin{array}{c}\text { UC } \\
120,000 \mathrm{~g}, 90 \mathrm{~min})\end{array}$ & Not disclosed & $5 \mathrm{mg} / \mathrm{kg}$ & $\begin{array}{c}\text { Mouse, K7M2 } \\
\text { (human } \\
\text { osteosarcoma) } \\
\text { xenograft } \\
\text { (NU/NU) }\end{array}$ & IV & LI-COR & $\begin{array}{c}\text { Spleen }>\text { liver }>\text { tumor, } \\
\text { lung }>\text { kidney, brain, heart }\end{array}$ & [86] \\
\hline $\begin{array}{l}\text { Membrane } \\
\text { integration }\end{array}$ & $\begin{array}{l}\text { Fluorescence } \\
\text { (Dil) }\end{array}$ & Wnt4-exosomes & $\begin{array}{l}\text { Mouse TEP1 } \\
\text { (primary thymic } \\
\text { epithelial cell) }\end{array}$ & TEI (Invitrogen) & $\begin{array}{c}\text { TEI } \\
\text { (pre-labeling) }\end{array}$ & $\begin{array}{c}\text { Not } \\
\text { disclosed }\end{array}$ & $\begin{array}{c}\text { Mouse } \\
(\mathrm{BALB} / \mathrm{c})\end{array}$ & IV & IVIS & $\begin{array}{c}\text { Thymus }>\text { lung, liver, } \\
\text { spleen }\end{array}$ & [87] \\
\hline $\begin{array}{l}\text { Membrane } \\
\text { integration }\end{array}$ & $\begin{array}{l}\text { Fluorescence } \\
\text { (DiR) }\end{array}$ & $\begin{array}{c}\text { CVs } \\
\text { (by sonication) }\end{array}$ & $\begin{array}{c}\text { hCMEC/D3 } \\
\text { B16 }\end{array}$ & $\begin{array}{c}\mathrm{UC} \\
(60,000 \mathrm{rpm}, 24 \mathrm{~h})\end{array}$ & SEC & $\begin{array}{c}200 \mu \mathrm{g} \text { of } \\
\text { lipid }\end{array}$ & $\begin{array}{c}\text { Mouse } \\
\text { (FVB albino) }\end{array}$ & ROVS & IVIS & $\begin{array}{c}\text { Liver }>\text { spleen, lung }> \\
\text { brain }\end{array}$ & [88] \\
\hline $\begin{array}{l}\text { Membrane } \\
\text { integration }\end{array}$ & $\begin{array}{l}\text { Fluorescence } \\
\quad \text { (DiR) }\end{array}$ & $\begin{array}{c}\text { Exosomes } \\
\text { (ALIX, CD63, } \\
\text { CD81, CD9, } \\
\text { TSG101) }\end{array}$ & $\begin{array}{l}\mathrm{C} 2 \mathrm{C} 12 \text { murine } \\
\text { myoblast cell }\end{array}$ & $\begin{array}{c}\mathrm{UC} \\
(100,000 \mathrm{~g}, 1 \mathrm{~h})\end{array}$ & Not disclosed & $30 \mu \mathrm{g}$ & $\begin{array}{c}\text { Mouse } \\
(\mathrm{C} 57 \mathrm{BL} / 6)\end{array}$ & IV & IVIS & Liver $>$ spleen $>$ lung & [89] \\
\hline $\begin{array}{l}\text { Membrane } \\
\text { integration }\end{array}$ & $\begin{array}{l}\text { Fluorescence } \\
\quad \text { (DiR) }\end{array}$ & Exosomes & BM-MSC & $\begin{array}{c}\text { UC } \\
(100,000 \mathrm{~g}, 3 \mathrm{~h})\end{array}$ & $\begin{array}{c}\mathrm{UC} \\
(100,000 \mathrm{~g}, \mathrm{ND})\end{array}$ & $8 \times 10^{9}$ & $\begin{array}{l}\text { Mouse } \\
\text { (C57BL/6) } \\
\text { Tumor vs. non } \\
\text { tumor }\end{array}$ & IP & IVIS & Liver, spleen, pancreas & [45] \\
\hline
\end{tabular}


Table 4. Cont.

\begin{tabular}{|c|c|c|c|c|c|c|c|c|c|c|c|}
\hline $\begin{array}{l}\text { Labeling } \\
\text { Method }\end{array}$ & Modality & $\begin{array}{c}\text { Nomenclature } \\
\text { (Markers) }\end{array}$ & Cell Source & Isolation Method & $\begin{array}{c}\text { Purification } \\
\text { after Labeling }\end{array}$ & $\begin{array}{c}\text { Dose } \\
\text { (/Head) }\end{array}$ & Animal Model & $\begin{array}{l}\text { Admin. } \\
\text { Route }\end{array}$ & $\begin{array}{l}\text { Imaging } \\
\text { Method }\end{array}$ & Tissue Distribution & Ref. \\
\hline $\begin{array}{l}\text { Membrane } \\
\text { integration }\end{array}$ & $\begin{array}{l}\text { Fluorescence } \\
\text { (PKH67) }\end{array}$ & $\begin{array}{l}\text { Exosomes } \\
\text { (CD63) }\end{array}$ & Mouse BM-MSC & UF + ExoQuick & ExoQuick & $30 \mu \mathrm{g}$ & $\begin{array}{c}\text { Mouse } \\
\text { (BALB/c) } \\
\text { TUBO tumor }\end{array}$ & IV & IVIS & $\begin{array}{l}\text { (24 h) Tumor }>\text { spleen }> \\
\text { kidney, liver, lung }\end{array}$ & [90] \\
\hline $\begin{array}{l}\text { Membrane } \\
\text { integration }\end{array}$ & $\begin{array}{l}\text { Fluorescence } \\
\text { (DiR) }\end{array}$ & $\begin{array}{l}\text { Exosomes } \\
\text { (TSG101, } \\
\text { CD81) }\end{array}$ & $\begin{array}{l}\text { Endothelial colony } \\
\text { forming cell } \\
\text { (ECFC) }\end{array}$ & $\begin{array}{c}\text { UC } \\
(100,000 \mathrm{~g}, 90 \mathrm{~min})\end{array}$ & $\begin{array}{c}\text { UC } \\
(100,000 \mathrm{~g})\end{array}$ & $20 \mu \mathrm{g}$ & Male FVB mice & IV & IVIS & $\begin{array}{l}\text { (4 h) kidney > liver, heart, } \\
\text { spleen, lung }\end{array}$ & [91] \\
\hline $\begin{array}{l}\text { Membrane } \\
\text { integration }\end{array}$ & $\begin{array}{l}\text { Fluorescence } \\
\text { (DiD) }\end{array}$ & $\begin{array}{c}\text { Exosomes } \\
\text { (TSG101, CD9, } \\
\text { HSP70; } \\
\text { GM130-) } \\
\end{array}$ & $\begin{array}{l}\text { Murine EO771 BC } \\
\text { cells }\end{array}$ & $\begin{array}{l}\text { Combination of } \\
\text { UF (100 kDa) and } \\
\text { SEC }\end{array}$ & $\begin{array}{c}\text { UC } \\
(100,000 \mathrm{~g}, \\
90 \mathrm{~min})\end{array}$ & $\begin{array}{c}20 \mu \mathrm{g} \\
\left(1.6 \times 10^{11}\right)\end{array}$ & $\begin{array}{c}\text { Mouse } \\
\text { (C57BL/6 or } \\
\text { BALB/C) }\end{array}$ & IV & $\begin{array}{l}\text { IVIS } \\
\text { organ } \\
\text { imaging }\end{array}$ & $\begin{array}{c}\text { Lung, }>\text { liver }>\text { spleen, } \\
\text { kidney }>\text { heart }>\text { bone } \\
\text { marrow }\end{array}$ & [92] \\
\hline $\begin{array}{l}\text { Membrane } \\
\text { integration }\end{array}$ & $\begin{array}{l}\text { Fluorescence } \\
\text { (DiD) }\end{array}$ & $\begin{array}{c}\text { Exosomes } \\
\text { (TSG101, CD9, } \\
\text { HSP70; } \\
\text { GM130-) }\end{array}$ & $\begin{array}{l}\text { Murine } 4 \mathrm{~T} 1 \mathrm{BC} \\
\text { cells }\end{array}$ & $\begin{array}{c}\mathrm{UC} \\
(100,000 \times g \\
90 \mathrm{~min})\end{array}$ & $\begin{array}{c}\mathrm{UC} \\
(100,000 \mathrm{~g}, \\
90 \mathrm{~min})\end{array}$ & $\begin{array}{c}20 \mu \mathrm{g} \\
\left(1.2 \times 10^{11}\right)\end{array}$ & $\begin{array}{c}\text { Mouse } \\
\text { (C57BL/6 or } \\
\text { BALB/C) }\end{array}$ & IV & $\begin{array}{l}\text { IVIS } \\
\text { organ } \\
\text { imaging }\end{array}$ & $\begin{array}{c}\text { Lung }>\text { liver }>\text { kidney }> \\
\text { spleen, heart, bone } \\
\text { marrow }\end{array}$ & [92] \\
\hline $\begin{array}{l}\text { Membrane } \\
\text { integration }\end{array}$ & $\begin{array}{l}\text { Fluorescence } \\
\text { (DiD) }\end{array}$ & Exosomes & $\begin{array}{l}\text { Murine } 67 \mathrm{NR} B C \\
\text { cells }\end{array}$ & $\begin{array}{c}\text { UC } \\
(100,000 \times g \\
90 \mathrm{~min})\end{array}$ & $\begin{array}{c}\text { UC } \\
(100,000 \mathrm{~g}, \\
90 \mathrm{~min})\end{array}$ & $\begin{array}{c}20 \mu \mathrm{g} \\
\left(1.2 \times 10^{11}\right)\end{array}$ & $\begin{array}{c}\text { Mouse } \\
\text { (C57BL/6 or } \\
\text { BALB/C) }\end{array}$ & IV & $\begin{array}{c}\text { IVIS } \\
\text { organ } \\
\text { imaging }\end{array}$ & $\begin{array}{c}\text { Lung }>\text { liver }>\text { kidney }> \\
\text { spleen, heart, bone } \\
\text { marrow }\end{array}$ & [92] \\
\hline $\begin{array}{l}\text { Membrane } \\
\text { integration }\end{array}$ & $\begin{array}{l}\text { Fluorescence } \\
\text { (DiR) }\end{array}$ & EVs & Undisclosed & NA & $\begin{array}{l}\text { UC ( } 120,000 \mathrm{~g}, \\
70 \mathrm{~min}) \mathrm{vs} . \\
\text { UF (100 } \\
\text { kDa)-SEC } \\
(\mathrm{S}-400)\end{array}$ & Undisclosed & $\begin{array}{c}\text { Mouse } \\
(\mathrm{BALB} / \mathrm{c})\end{array}$ & IV & $\begin{array}{c}\text { IVIS } \\
\text { organ } \\
\text { imaging }\end{array}$ & $\begin{array}{c}\text { (UC) liver > lung, spleen > } \\
\text { kidney } \\
\text { (UF-SEC) liver }>\text { spleen > } \\
\text { lung }>\text { kidney }\end{array}$ & [93] \\
\hline $\begin{array}{l}\text { Membrane } \\
\text { integration }\end{array}$ & $\begin{array}{l}\text { Fluorescence } \\
\quad \text { (DiR) }\end{array}$ & $\begin{array}{l}\text { EVs } \\
\text { (ALIX, } \\
\text { TSG101) }\end{array}$ & HEK293T cells & $\begin{array}{c}\mathrm{UC} \\
(110,000 \mathrm{~g}, 70 \mathrm{~min})\end{array}$ & $\begin{array}{c}\text { NA } \\
\text { (pre-labeling } \\
\text { before UC) }\end{array}$ & $\begin{array}{l}1.5 \times 10^{10} \\
1,0 \times 10^{10^{\prime}} \\
0.25 \times 10^{10} \\
\text { p/g BW }\end{array}$ & $\begin{array}{c}\text { Mouse } \\
\text { (NMRI or C57BL/6) }\end{array}$ & $\begin{array}{l}\text { IV } \\
\text { IP } \\
\text { SC }\end{array}$ & IVIS & $\begin{array}{c}\text { (IV) liver }>\text { GI-tract, } \\
\text { spleen }>\text { lung }>\text { pancreas } \\
\text { (IP) liver, GI-tract, } \\
\text { pancreas }>\text { spleen, lung } \\
\text { (SC) GI-tract > liver > } \\
\text { pancreas, lung > spleen }\end{array}$ & [68] \\
\hline $\begin{array}{l}\text { Membrane } \\
\text { integration }\end{array}$ & $\begin{array}{l}\text { Fluorescence } \\
\text { (DiR) }\end{array}$ & $\begin{array}{c}\text { EVs } \\
\text { (ALIX, } \\
\text { TSG101) }\end{array}$ & DC cells & $\begin{array}{c}\mathrm{UC} \\
(110,000 \mathrm{~g}, 70 \mathrm{~min})\end{array}$ & $\begin{array}{c}\text { NA } \\
\text { (pre-labeling } \\
\text { before UC) }\end{array}$ & $\begin{array}{l}1.0 \times 10^{10} \\
\mathrm{p} / \mathrm{g} B W\end{array}$ & $\begin{array}{c}\text { Mouse } \\
\text { (NMRI or C57BL/6) }\end{array}$ & IV & IVIS & $\begin{array}{l}\text { Liver }>\text { spleen }>\text { GI-tract, } \\
\text { lung }>\text { pancreas }\end{array}$ & [68] \\
\hline $\begin{array}{l}\text { Membrane } \\
\text { integration }\end{array}$ & $\begin{array}{l}\text { Fluorescence } \\
\quad \text { (DiR) }\end{array}$ & $\begin{array}{c}\text { EVs } \\
\text { (ALIX, } \\
\text { TSG101) }\end{array}$ & $\mathrm{C} 2 \mathrm{C} 12$ cells & $\begin{array}{c}\mathrm{UC} \\
(110,000 \mathrm{~g}, 70 \mathrm{~min})\end{array}$ & $\begin{array}{c}\text { NA } \\
\text { (pre-labeling } \\
\text { before UC) }\end{array}$ & $\begin{array}{l}1.0 \times 10^{10} \\
\mathrm{p} / \mathrm{g} \text { BW }\end{array}$ & $\begin{array}{c}\text { Mouse } \\
\text { (NMRI or C57BL/6) }\end{array}$ & IV & IVIS & $\begin{array}{l}\text { Liver }>\text { spleen }>\text { GI-tract }> \\
\quad \text { lung }>\text { pancreas }\end{array}$ & {$[68]$} \\
\hline $\begin{array}{l}\text { Membrane } \\
\text { integration }\end{array}$ & $\begin{array}{l}\text { Fluorescence } \\
\text { (DiR) }\end{array}$ & $\begin{array}{c}\text { EVs } \\
\text { (ALIX, } \\
\text { TSG101) }\end{array}$ & B16F10 cells & $\begin{array}{c}\mathrm{UC} \\
(110,000 \mathrm{~g}, 70 \mathrm{~min})\end{array}$ & $\begin{array}{c}\text { NA } \\
\text { (pre-labeling } \\
\text { before UC) }\end{array}$ & $\begin{array}{l}1.0 \times 10^{10} \\
\mathrm{p} / \mathrm{g} B W\end{array}$ & $\begin{array}{c}\text { Mouse } \\
\text { (NMRI or C57BL/6) }\end{array}$ & IV & IVIS & $\begin{array}{l}\text { Liver }>\text { GI-tract, spleen, } \\
\text { lungs }>\text { pancreas }\end{array}$ & [68] \\
\hline $\begin{array}{l}\text { Membrane } \\
\text { integration }\end{array}$ & $\begin{array}{l}\text { Fluorescence } \\
\quad \text { (DiR) }\end{array}$ & $\begin{array}{l}\text { Exosome } \\
\text { (CD63, } \\
\text { flotillin-1) }\end{array}$ & BMSCs & $\begin{array}{c}\text { UF (3 } \\
\text { kDa)-ExoQuick-TC }\end{array}$ & ExoQuick-TC & $500 \mu \mathrm{g}$ & C57BL/KaLwRij & IV & Fluobean 800 & BM, spleen, liver & [94] \\
\hline
\end{tabular}


Table 4. Cont.

\begin{tabular}{|c|c|c|c|c|c|c|c|c|c|c|c|}
\hline $\begin{array}{l}\text { Labeling } \\
\text { Method }\end{array}$ & Modality & $\begin{array}{c}\text { Nomenclature } \\
\text { (Markers) }\end{array}$ & Cell Source & Isolation Method & $\begin{array}{c}\text { Purification } \\
\text { after Labeling }\end{array}$ & $\begin{array}{c}\text { Dose } \\
\text { (/Head) }\end{array}$ & Animal Model & $\begin{array}{l}\text { Admin. } \\
\text { Route }\end{array}$ & $\begin{array}{l}\text { Imaging } \\
\text { Method }\end{array}$ & Tissue Distribution & Ref. \\
\hline $\begin{array}{l}\text { Membrane } \\
\text { integration }\end{array}$ & $\begin{array}{l}\text { Fluorescence } \\
\text { (DiD) }\end{array}$ & $\begin{array}{c}\text { EVs } \\
(\mathrm{CD} 44, \mathrm{CD} 105, \\
\text { CD90, } \\
\alpha 5 \text {-integrin }) \\
\end{array}$ & MSCs & $\begin{array}{c}\mathrm{UC} \\
(100,000 \mathrm{~g}, 1 \mathrm{~h})\end{array}$ & UC & $200 \mu \mathrm{g}$ & $\begin{array}{c}\text { Mouse } \\
\text { CD1 with or without } \\
\text { glycerol-induced } \\
\text { AKI }\end{array}$ & IV & $\begin{array}{l}\text { IVIS } \\
\text { organ } \\
\text { imaging }\end{array}$ & $\begin{array}{c}\text { (24 h) } \text { liver > spleen > } \\
\text { lung }\end{array}$ & [95] \\
\hline Encapsulation & $\underset{99 \mathrm{~m}}{\mathrm{RI}}$ & $\begin{array}{l}\text { Exosome } \\
\text { mimetics }\end{array}$ & Rat RBCs & $\begin{array}{c}\text { UC } \\
(100,000 \mathrm{~g}, 1 \mathrm{~h})+ \\
\text { DGUC }\end{array}$ & $\begin{array}{l}\text { Centrifugation } \\
\text { (not disclosed } \\
\text { in detail) }\end{array}$ & $37 \mathrm{Mbq}$ & $\begin{array}{c}\text { Mouse } \\
\text { (C57BL/6, male) }\end{array}$ & IV & $\begin{array}{l}\text { Gamma } \\
\text { camera } \\
\text { imaging }\end{array}$ & $\begin{array}{c}\text { Liver, spleen, kidney > } \\
\text { thyroid, stomach, lung, } \\
\text { blood, intestine }>\text { heart, } \\
\text { muscle, bone }\end{array}$ & [65] \\
\hline Encapsulation & $\begin{array}{c}\text { MR } \\
\text { gold } \\
\text { nanoparticles }\end{array}$ & $\begin{array}{l}\text { Exosomes } \\
\text { (CD9) }\end{array}$ & Human MSCs & $\begin{array}{c}\text { UC } \\
(100,000 \mathrm{~g}, 70 \mathrm{~min})\end{array}$ & $\begin{array}{c}\mathrm{UC} \\
(100,000 \mathrm{~g}, 2 \mathrm{~h})\end{array}$ & $2.8 \times 10^{9}$ & $\begin{array}{c}\text { Mouse } \\
\text { (C57bl/6, male) }\end{array}$ & $\begin{array}{l}\text { IV } \\
\text { IN }\end{array}$ & $\mathrm{CT}$ & $\begin{array}{l}\text { (IV) lung, liver > spleen > } \\
\text { kidney, brain, blood } \\
\text { (IN) lung > spleen > } \\
\text { kidney, brain, blood, liver }\end{array}$ & [96] \\
\hline Encapsulation & $\begin{array}{c}\text { RI } \\
{ }^{99 \mathrm{~m}} \mathrm{Tc}-\mathrm{HMPAO}\end{array}$ & $\begin{array}{l}\text { Exosome } \\
\text { mimetic }\end{array}$ & RAW264.7 & $\begin{array}{c}\text { DGUC } \\
(100,000 \mathrm{~g}, 2 \mathrm{~h})\end{array}$ & $\begin{array}{c}\text { SEC } \\
\text { (MW3000) }\end{array}$ & $\begin{array}{c}7.4-14.8 \\
\mathrm{Mbq} \\
(29-64 \mu \mathrm{g})\end{array}$ & $\begin{array}{c}\text { Mouse } \\
(\mathrm{BALB} / \mathrm{c})\end{array}$ & IV & SPECT/CT & $\begin{array}{l}(5 \mathrm{~h}) \text { liver }>\text { kidney }> \\
\text { spleen }>\text { intestine }>\text { lung, } \\
\text { heart, stomach, heart }> \\
\text { bone, muscle, blood }\end{array}$ & [97] \\
\hline $\begin{array}{l}\text { Encapsulation } \\
\text { by } \\
\text { transfection }\end{array}$ & $\begin{array}{l}\text { MR } \\
\text { SPIO }\end{array}$ & $\begin{array}{l}\text { Exosomes } \\
\text { (CD9, CD63) }\end{array}$ & MDA-MB-231 & ExoQuick & NA & $100 \mu \mathrm{g}$ & Mouse & IV & $\begin{array}{l}\text { MPI } \\
\text { CT }\end{array}$ & Liver & [75] \\
\hline $\begin{array}{l}\text { Encapsulation } \\
\text { by Sonication }\end{array}$ & $\begin{array}{l}\text { Fluorescence } \\
\text { Chlorin e6 } \\
\text { (Ce6) }\end{array}$ & $\begin{array}{c}\text { Tumor } \\
\text { targeting EVs }\end{array}$ & RAW264.7 & $\begin{array}{c}\mathrm{UC} \\
(100,000 \mathrm{~g}, 70 \mathrm{~min})\end{array}$ & $\begin{array}{c}\text { UC } \\
(100,000 \mathrm{~g}, \\
70 \mathrm{~min})\end{array}$ & $10 \mathrm{mg} / \mathrm{kg}$ & $\begin{array}{c}\text { Mouse } \\
\text { (BALB/c nu/nu) } \\
\text { with HCT116 tumor }\end{array}$ & IV & $\begin{array}{c}\text { Image } \\
\text { Station } 4000 \\
\text { MM }\end{array}$ & $\begin{array}{c}\text { Tumor }>\text { liver }>\text { lung, } \\
\text { kidney, spleen, brain, } \\
\text { heart }\end{array}$ & [76] \\
\hline
\end{tabular}

Abbreviations: AKI, acute kidney injury; BC, breast cancer; BLI, bioluminescence imaging; BMSC, bone marrow stromal cell; BW, body weight; CV, cellular vesicle; CT, computed tomography; DGUC, density-gradient ultracentrifugation; EPCs, endothelial progenitor cells; FI, fluorescence intensity; FP, fluorescence protein; GNP, gold nanoparticle; ICP-MS, magnetic resona vesicle; RI, radioisotope; RLU, relative luminescence unit; ROVS, retro-orbital venous sinus; SC, subcutaneous; SEC, size exclusion chromatography; SPECT, single-photon emission computed tomography; SPIO, superparamagnetic iron oxide; TEI, total exosome isolation reagent; UC, ultracentrifugation; UC-MSC, umbilical cord MSC; UF, ultrafiltration. 
Among the 29 papers reviewed, eight papers reported the labeling of exosomes by covalent binding to probes. The most commonly used labeling modality for covalent binding was radioisotope labeling (five out of eight) (Table 4). Fluorescent dyes (three out of eight) were also used for covalent binding. The advantage of covalent binding is the low risk of pseudo-positive signals caused by the spontaneous release of probes without covalent bonds. However, careful analysis is required since modification of surface proteins by the covalent binding of probes may change the interaction of exosomes and their target tissues or cells $[73,76]$.

The most widely used labeling method is the membrane integration of lipophilic fluorescent dyes (Figure 2, left). Fifty percent of the studies evaluated used the membrane integration strategy with lipophilic fluorescent dyes (Table 4). For membrane integration, fluorescent probes were overwhelmingly selected over other methods (Figure 2, right). DiR was the most frequently used lipophilic fluorescent dye (Figure 3). DiR is a dialkylcabarbocyanine with NIR fluorescence which is ideal for in vivo imaging since it has low absorption by biological materials [98]. The FDA-approved NIR dye Indocyanine Green (ICG) is also able to label exosomes [99,100]. A potential issue is the possibility of lipophilic dyes forming micelles in the liquid [73]. Therefore, it is of utmost importance to compare the number of particles before and after labeling with lipophilic dyes. In addition, it is necessary to include a proper negative control containing the appropriate amount of lipophilic dye [45]. A buffer solution with lipophilic dyes incubated and processed using the same procedures employed for the exosomes with lipophilic dyes may also be a good negative control.

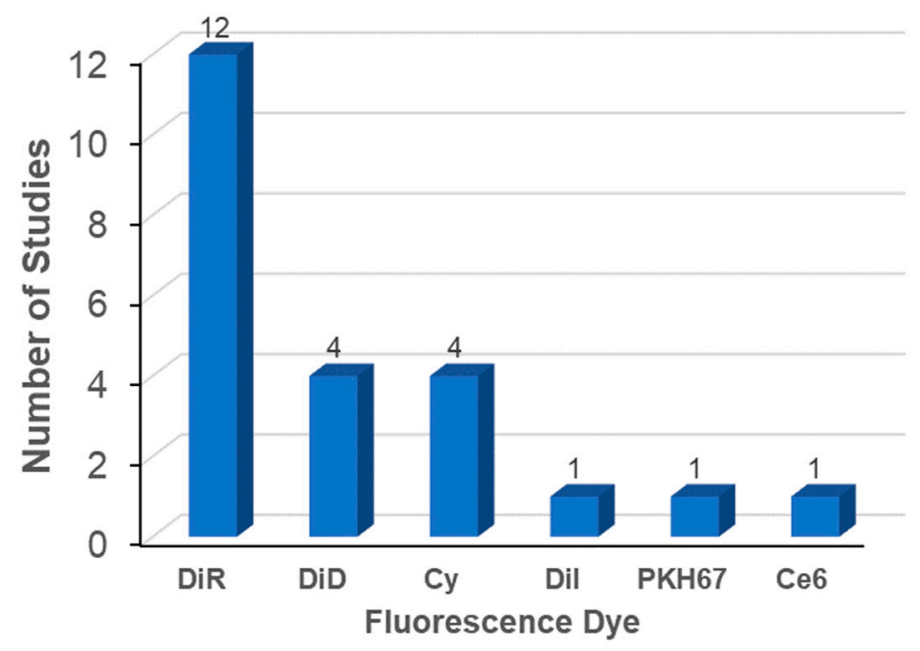

Figure 3. Fluorescent dyes used in biodistribution analysis of exosomes.

\subsubsection{Characterization of Exosomes}

One unexpected finding is that many studies used exosomes or EVs without characterization. As mentioned earlier, QC of exosomes is essential for both reproducible basic exosome research and the development of exosome therapeutics. The ISEV also proposed minimal requirements in the MISEV2018 guidelines for the identification of exosomes by analyzing specific markers [21]. Surprisingly, we found that approximately $40 \%$ of studies did not include the analysis of specific markers (Figure 4). Other than publications with exosome-like vesicles from microorganisms or exosome mimetics, 11 publications did not provide the results of specific marker analysis (Table 4). Although the results of NTA or electron microscopic analysis were reported in some cases, these results are not sufficient to confirm the identity of the exosomes used in the studies. More importantly, analysis of specific markers is especially important to compare the properties of exosomes and analyze the recovery rate between before and after labeling. 


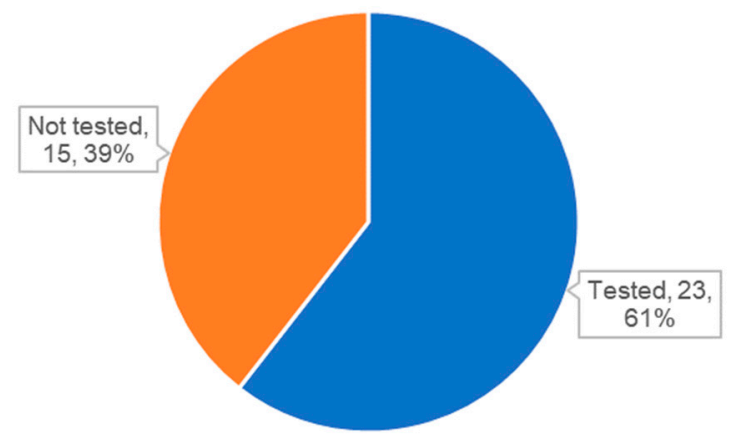

Figure 4. Status of analysis for specific markers for exosomes or extracellular vesicles (EVs).

\subsubsection{Exosome Isolation Methods}

Selection of the appropriate isolation method is essential for the industrial development of exosome-based therapeutics [50,51]. As shown in Figure 5, the dominant method for isolating exosomes is UC. This implies that UC is still the general method used to isolate exosomes in most academic settings, although the method is not ideal for the mass production of exosomes for the development of therapeutics. SEC was reported in only one publication [82]. In a few studies, precipitation with commercial kits was used to isolate exosomes. The process should be carefully monitored to determine whether the additives used for precipitation such as PEG have adverse effects on the labeling or biodistribution of exosomes. Ideally, these additives should be removed from the final exosome products before administration to an experimental animal. One publication reported that there was no significant difference in the biodistribution of exosomes isolated using UC or SEC [93].

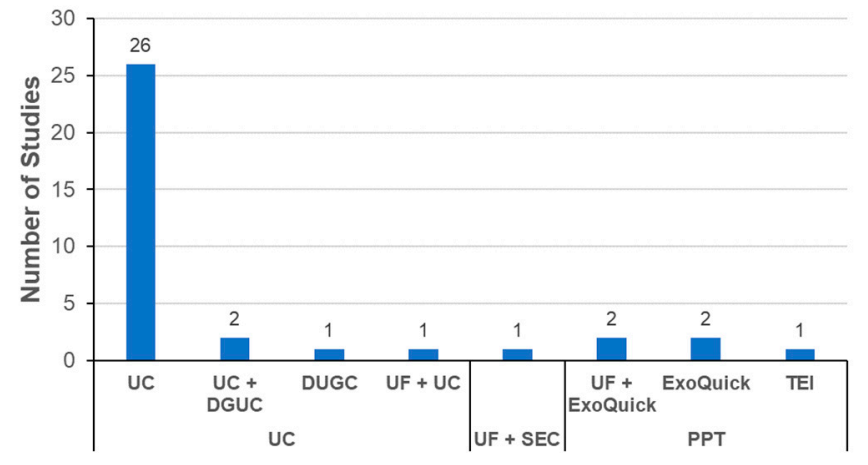

Figure 5. Isolation methods of exosomes in literature of exosome biodistribution.

Another important aspect to consider is the removal of excess unlabeled probes from labeled exosomes. UC was the most commonly used method for removing free probes in the studies evaluated (Figure 6). Interestingly, SEC was the second most frequently method for removing free probes. One drawback of SEC was the increase of sample volume with multiple fractions during the isolation process. To avoid this, methods based on the gel filtration (GF) principle are possible alternatives to conventional SEC. Commercial GF columns are already available to remove free probes by simple centrifugation without a significant increase in the sample volume [44,74,82,97]. Precipitation methods were also used to remove free probes. Again, the possibility of adverse effects from the additives used for precipitation cannot be excluded without further steps to remove the additives. 


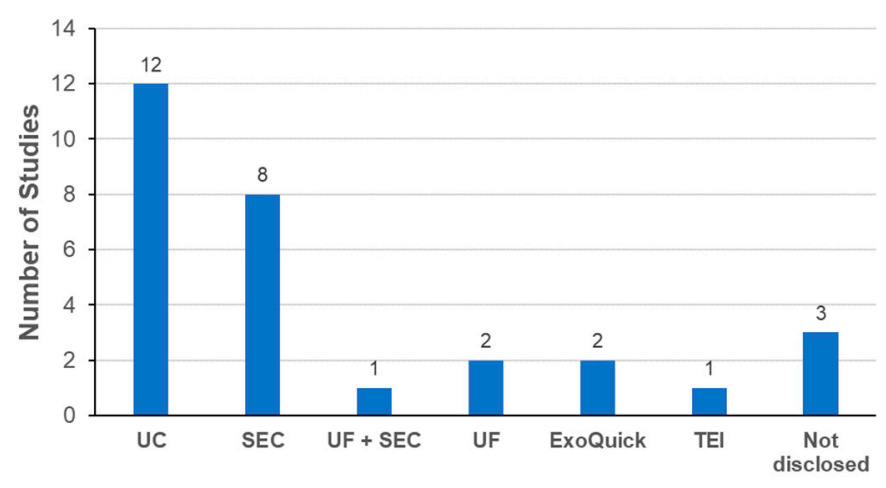

Figure 6. Methods to remove unlabeled probes from labeled exosomes.

\subsubsection{Determination of Exosome Dose}

Determination of the exosome dose for biodistribution analysis is another essential factor. Since exosomes are composed of lipids, proteins, and nucleic acids, it is possible to determine the exosome dose from the total amounts of lipids, proteins, or nucleic acids, respectively. It is also possible to determine the exosome dose from the total number of particles [21]. As shown in Figure 7, the most frequently used parameter for exosome dose determination was the amount of total proteins, followed by the number of particles. Parallel description of the amount of proteins and the number of particles was also reported in three publications as suggested by the ISEV in MISEV2018 [21]. The range of total proteins was from 10 to $500 \mu \mathrm{g}$ per animal and that of the number of particles was from $2.8 \times 10^{9}$ to approximately $3.8 \times 10^{11}$ particles per animal (Table 4 ). Interestingly, all publications exclusively reported the use of mice for exosome biodistribution analysis. Recently, increasing evidence suggests that the use of zebrafish is a promising new approach to study in vivo physiology and pathology of exosomes [101]. Indeed, the transparency and small size of the zebrafish embryo enables live whole-body imaging analysis for better understanding of biodistribution including exosome uptake and fate.

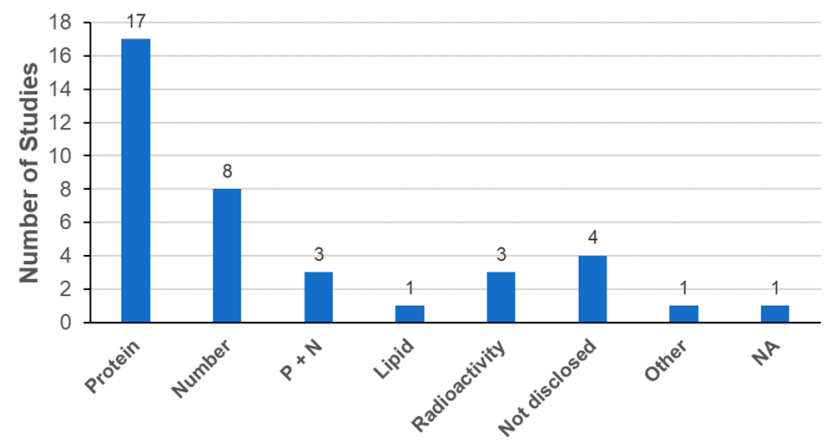

Figure 7. Determination of exosome dose in biodistribution. Abbreviations: Protein, total amount of proteins; number, total number of particles; $\mathrm{P}+\mathrm{N}$, total amount of proteins with total number of particles; Lipid, total amount of lipids.

\subsubsection{Routes of Administration}

For in vivo analysis of exosome distribution, intravenous (IV) injection of exosomes was the dominant (78\%) administration route (Figure 8). Three publications used intraperitoneal injection as an alternative route. The administration of exosomes through intranasal, hock, subcutaneous, and retro-orbital venous sinus routes was rarely used. The most frequent accumulation tissues for exosomes after IV injection were reported as the liver, lung, spleen, and kidney (Table 4). Although the modification of surface proteins such as glycosylation may have affected the in vivo distribution of exosomes in a few reports [66,67], additional studies with more animals seems to be necessary 
for more accurate analysis. It was also reported that there was a difference in the biodistribution of exosomes according to the exosome-producing cells [68]. Further studies will be needed to determine the significance of these findings.

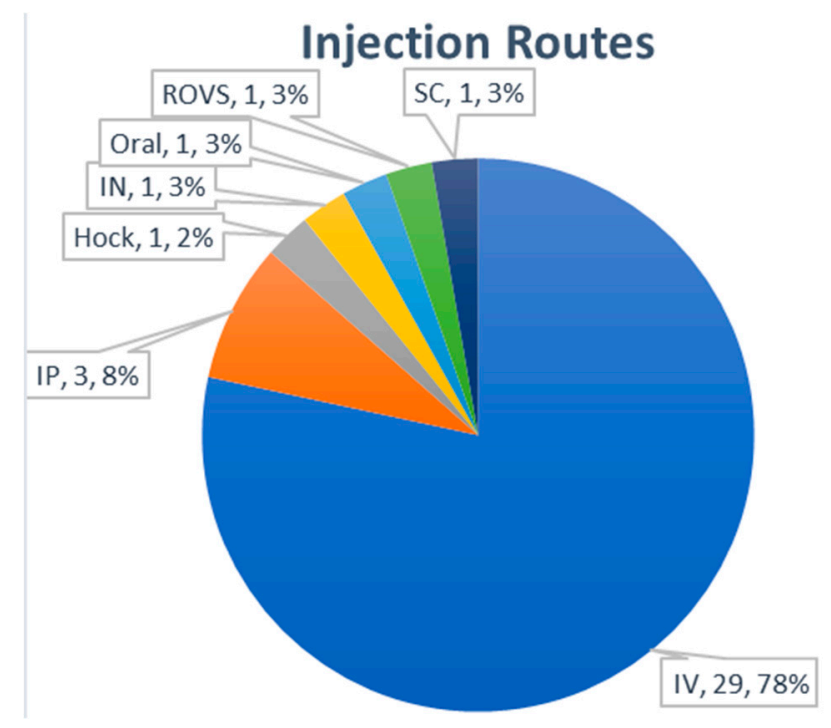

Figure 8. Administration route of exosomes for biodistribution analysis.

\subsection{Therapeutic Implication of Exosome Biodistribution}

As mentioned, the information on in vivo distribution of exosomes provides basis for prediction of dose and potential side effects. In addition, it also provides the clue for target tissues of specific therapeutic application. Several studies have already provided the relevance between biodistribution and therapeutic effects.

\subsubsection{Natural Targeting Properties of Exosomes}

Tissue tropism is dependent on the surface composition of exosomes [102]. Different integrin compositions determine the organotropism of exosomes derived from different tumors [103]. Secreted proteins such as Wnt 4 and TGF- $\beta 1$ have been identified to be associated with exosomes $[53,104]$. Wnt4-associated exosomes derived from thymic epithelial cells accumulated in the thymus of mice and this tropism was further enhanced by overexpression of Wnt4 in the originating cells, which might induce regeneration of thymus [87]. More interestingly, EVs from Helicobactor pyroli was reported to preferentially accumulate in stomach and induce inflammatory responses [78].

\subsubsection{Tumor-Homing of Exosomes}

Tumor-homing exosomes could be exploited as targeting delivery vehicles. As an example, hypoxic cancer-homing exosomes, which were loaded with olaparib, demonstrated retarded tumor growth in xenograft mice [75]. Interestingly, exosomes derived from MSCs (MSC-exosomes) have been reported to exhibit tumor-homing properties similar to those of MSCs [105]. Human UC-MSC-exosomes were reported to accumulate in tumor of mouse osteosarcoma K7M2 cells in nude mice [86]. These UC-MSC-exosomes reduced proliferation of human osteosarcoma 143B and mouse osteosarcoma K7M2 cells in vitro in a dose-dependent manner by inducing apoptosis. The tumor-homing of MSC-exosomes has been successfully adopted to deliver therapeutic miRNAs to reduce tumors in xenograft mice with patient-derived pancreatic cancer [45], and syngeneic breast tumors in mice [90]. Interestingly, beyond organotropism of tumor exosomes, generalized tropism of tumor exosomes toward neoplastic tissues from different types or species have also been reported [106]. 


\subsubsection{Accumulation of MSC-Exosomes in Damaged Tissues}

An interesting finding is that MSC-exosomes were preferentially accumulated in the kidneys of mice with glycerol-induced acute kidney injury compared to the distribution in normal mice [95]. The application of MSCs as a cell-based therapy for acute or chronic kidney disease has been studied [107]. MSC-exosomes have also been reported to be effective for kidney diseases in various animal models [108]. Since MSCs are known to accumulate in damaged tissues through the interactions of receptors on the MSCs and target tissues [109,110], it is highly probable that MSC-exosomes are also localized in damaged tissues due to these receptor interactions. Similarly, exosomes from endothelial progenitor cells showed accumulation in ischemic kidney to prevent ischemic injury through CXCR4-SDF- $1 \alpha$ interaction [91].

\subsubsection{Tissue Targeting by Exosome Engineering}

In addition to natural cell-targeting abilities, it is also possible to engineer exosomes to target specific tissues or cells [102]. PEGylation of exosomes resulted in targeted accumulation of exosomes derived from cardiosphere-derived cells in ischemic myocardium in mice [111]. Targeted delivery of exosomes by genetic modification of their surface proteins has been also been reported: (1) brain targeting by rabies viral glycoprotein (RVG) peptide or RGD motif [19,112]; and (2) tumor targeting by EGFR-specific nanobodies or HER2-specific single-chain variable fragments [113]. Recently a peptide CP05, which binds CD63, was introduced as an anchor for homing moieties to change the biodistribution of exosomes [89]. Engineered exosomes with tumor specificity could be also used to delivery chemotherapeutic agents to reduce tumors in vivo [76]. In fact, exosomes are being developed as drug carriers since they are a natural-born delivery vehicle. A wide variety of therapeutic molecules can be delivered by exosomes, including small molecules [114,115], anti-cancer drugs such as paclitaxel [116] and doxorubicin [117], and oncolytic viruses as well [116,118,119].

\section{Conclusions}

Exosomes from different cell types have unique features according to their originating cell types and are being rapidly developed as therapeutic agents, drug delivery vehicles, and liquid biopsy markers. Exosomes derived from MSCs are attractive for next generation cell-free therapeutics since they recapitulate MSC capabilities of repair/regeneration, anti-inflammation, and immune modulation and overcome the potential risk and limitations of cell-based therapeutics.

Analysis of the biodistribution of exosomes is an essential step to determine the therapeutic dose and predict the potential side effects of exosomes. However, this is extremely challenging because of the nano-range of their sizes and complex nature of their composition. QC of produced exosomes is also extremely important to ensure reproducible results. Additionally, the labeling methods and analytical modalities are limited by the characteristics of exosomes produced by living cells. A growing number of studies and advances in the methods and modalities are expected to provide proper evaluation solutions for high quality exosomes therapeutics in the near future.

Author Contributions: Conceptualization, Y.W.Y. and J.H.L.; writing-original draft preparation, Y.W.Y.; writing-review and editing, Y.W.Y., J.H.L., S.-Y.K., C.-G.P., D.H.H., S.R.P., J.Y., and B.S.C.; funding acquisition, Y.W.Y., S.-Y.K., and B.S.C.; supervision, B.S.C. All authors have read and agreed to the published version of the manuscript.

Funding: This study was partially supported by a grant (19172MFDS166) from the Ministry of Food and Drug Safety in 2019. This study was also partially supported by ExoCoBio Inc.

Conflicts of Interest: Y.W.Y. and B.S.C. are founders and stockholders of ExoCoBio Inc. Y.W.Y., J.H.L., D.H.H., S.R.P., J.Y., and B.S.C. are employees of ExoCoBio Inc. 


\section{Abbreviations}

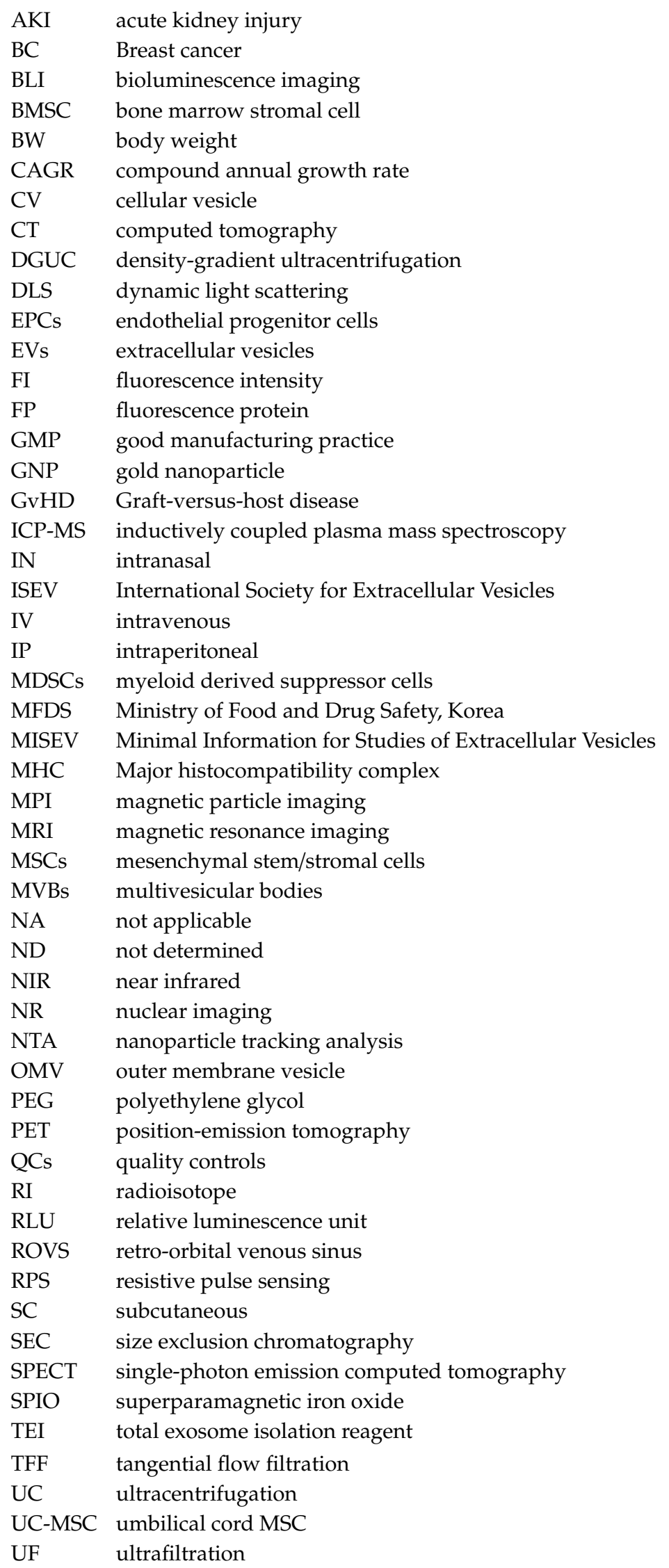




\section{References}

1. Deatherage, B.L.; Cookson, B.T. Membrane vesicle release in bacterial, eukaryotes, and archeas: A conserved yet underappreciated aspect of microbial life. Infect. Immun. 2012, 80, 1948-1957. [CrossRef]

2. Chargaff, E.; West, R. The biological significance of the thromboplatic protein of blood. J. Biol. Chem. 1946, 166, 189-197.

3. Wolf, P. The nature and significance of platelet products in human plasma. Br. J. Haematol. 1967, 13, $269-288$. [CrossRef]

4. Johnstone, R.M.; Adam, M.; Hammond, J.R.; Orr, L.; Turbide, C. Vesicle formation during reticulocyte maturation. Association of plasma membrane activities with released vesicles (exosomes). J. Biol. Chem. 1987, 262, 9412-9420.

5. Valadi, H.; Ekstrom, K.; Bossios, A.; Sjostrand, M.; Lee, J.J.; Lotvall, J.O. Exosome-mediated transfer of mRNAs and microRNAs is a novel mechanism of genetic exchange between cells. Nat. Cell Biol. 2007, 9, 654-659. [CrossRef]

6. Timmers, L.; Lim, S.K.; Arslan, F.; Armstrong, J.S.; Hoefer, I.E.; Doevendans, P.A.; Piek, J.J.; El Oakley, R.M.; Choo, A.; Lee, C.N.; et al. Reduction of myocardial infarct size by human mesenchymal stem cell conditioned medium. Stem Cell Res. 2008, 1, 129-137. [CrossRef]

7. Knox, K.W.; Vesk, M.; Work, E. Relation between excreted lipopolysaccharide complexes and surface structures of a lysine-limited culture of Escherichia coli. J. Bacteriol. 1966, 92, 1206-1217. [CrossRef]

8. Aaronson, S.; Behrens, U.; Orner, R.; Haines, T.H. Ultrastructure of intracellular and extracellular vesicles, membranes, and myelin figures produces by Ochromonas Danica. J. Ultrastruct. Res. 1971, 35, 418-430. [CrossRef]

9. Harding, C.; Heuser, J.; Stahl, P. Receptor-mediated endocytosis of transferrin and recycling of the transferrin receptor in rat reticulocytes. J. Cell Biol. 1983, 97, 329-339. [CrossRef]

10. Pan, B.T.; Johnstone, R.M. Fate of the transferring receptor during maturation of sheep reticulocytes in vitro: Selective externalization of the receptor. Cell 1983, 33, 967-978. [CrossRef]

11. Zitvogel, L.; Regnault, A.; Lozier, A.; Wolfers, J.; Flament, C.; Tenza, D.; Ricciardi-Castagnoli, P.; Raposo, G.; Amigorena, S. Eradication of established murine tumors using a novel cell-free vaccine: Dendritic cell-derived exosomes. Nat. Med. 1998, 4, 594-600. [CrossRef]

12. Tatischeff, I.; Bomsel, M.; de Paillerets, C.; Durand, H.; Geny, B.; Segretain, D.; Turpin, E.; Alfsen, A. Dictyostelium discoideum cells shed vesicles with associated DNA and vital stain Hoeschst 33342. Cell. Mol. Life Sci. 1998, 54, 476-487. [CrossRef]

13. Wolfers, J.; Lozier, A.; Raposo, G.; Rengnault, A.; Thery, C.; Masurier, C.; Flament, C.; Pousieux, S.; Faure, F.; Tursz, T.; et al. Tumor-derived exosomes are a source of shared tumor rejection antigens for CTL cross-priming. Nat. Med. 2001, 7, 297-303. [CrossRef]

14. Rodrigues, M.L.; Nimrichter, L.; Oliveira, D.L.; Frases, S.; Miranda, K.; Zaragoza, O.; Alvarez, M.; Nakouzi, A.; Feldmesser, M.; Casadevall, A. Vesicular polysaccharide export in Cryptococcus neoformans is a eukaryotic solution to the problem of fungal trans-cell wall transport. Eukaryot. Cell 2007, 6, 48-59. [CrossRef]

15. Soler, N.; Marguet, E.; Verbavatz, J.M.; Forterre, P. Virus-like vesicles and extracellular DNA produced by hyperthermophilic archaea of the order Thermococcales. Res. Microbiol. 2008, 159, 390-399. [CrossRef]

16. Regente, M.; Corti-Monzon, G.; Maldonado, A.M.; Pinedo, M.; Jorrin, J.; de la Canal, L. Vesicular fractions of sunflower apoplastic fluids are associated with potential exosome marker proteins. FEBS Lett. 2009, 583, 3363-3366. [CrossRef]

17. Lee, E.Y.; Choi, D.Y.; Kim, D.K.; Kim, J.W.; Park, J.O.; Kim, S.; Kim, S.H.; Desiderio, D.M.; Kim, Y.K.; Kim, K.P.; et al. Gram-positive bacteria produce membrane vesicles: Proteomics-based characterization of Staphylococcus aureus-derived membrane vesicles. Proteomics 2009, 9, 5425-5436. [CrossRef]

18. Araldi, E.; Kramer-Albers, E.M.; Hoen, E.N.; Peinado, H.; Psonka-Antonczyk, K.M.; Rao, P.; van Niel, G.; Yanez-Mo, M.; Nazarenko, I. International society for extracellular vesicles: First annual meeting, April 17-21, 2012: ISEV-2012. J. Extracell. Vesicles 2012, 1, 19995. [CrossRef]

19. Alvarez-Erviti, L.; Seow, Y.; Yin, H.; Betts, C.; Lakhal, S.; Wood, M.J. Delivery of siRNA to the mouse brain by systemic injection of targeted exosomes. Nat. Biotechnol. 2011, 29, 341-345. [CrossRef] 
20. Kordelas, L.; Rebmann, V.; Ludwig, A.K.; Radtke, S.; Ruesing, J.; Doeppner, T.R.; Epple, M.; Horn, P.A.; Beelen, D.W.; Giebel, B. MSC-derived exosomes: A novel tool to treat therapy-refractory graft-versus-host disease. Leukemia 2014, 28, 970-973. [CrossRef]

21. Thery, C.; Witwer, K.W.; Aikawa, E.; Alcaraz, M.J.; Anderson, J.D.; Andriantsitohaina, R.; Antoniou, A.; Arab, T.; Archer, F.; Atkin-Smith, G.K.; et al. Minimal information for studies of extracellular vesicles 2018 (MISEV2018): A position statement of the International Society for Extracellular Vesicles and update of the MISEV2014 guidelines. J. Extracell. Vesicles 2018, 7, 1535750. [CrossRef]

22. National Institute of Food and Drug Safety Evaluation. Guideline on Quality, Non-Clinical and Clinical Assessment of Extracellular Vesicles Therapy Products. 2018. Available online: www.nifds.go.kr/brd/m_15/ down.do?brd_id=167\&seq=12625\&data_tp=A\&file_seq=1 (accessed on 13 December 2019).

23. Samuel, M.; Bleackley, M.; Anderson, M.; Mathivanan, S. Extracellular vesicles including exosomes in cross kingdom regulation: A viewpoint from plant-fungal interactions. Front. Plant Sci. 2015, 6, 766. [CrossRef] [PubMed]

24. Park, K.S.; Bandeira, E.; Shelke, G.V.; Lasser, C.; Lotvall, J. Enhancement of therapeutic potential of mesenchymal stem cell-derived extracellular vesicles. Stem Cell Res. Ther. 2019, 10, 288. [CrossRef] [PubMed]

25. Stemersch, S.; de Smedt, S.C.; Raemdonck, K. Therapeutic and diagnostic applications of extracellular vesicels. J. Contorol. Release 2016, 244, 167-183. [CrossRef] [PubMed]

26. Wiklander, O.P.B.; Brennan, M.A.; Lotvall, J.; Breakefield, X.O.; El Andaloussi, S. Advances in therapeutic applications of extracellular vesicles. Sci. Transl. Med. 2019, 11, eaav8521. [CrossRef]

27. Kanada, M.; Bachmann, M.H.; Contag, C.H. Signaling by extracellular vesicles advances cancer hallmarks. Trends Cancer 2016, 2, 84-94. [CrossRef]

28. Mathivanan, S.; Ji, H.; Simpson, R.J. Exosomes: Extracellular organelles important in intercellular communication. J. Proteom. 2010, 73, 1907-1920. [CrossRef]

29. Thery, C.; Zitvogel, L.; Amigorena, S. Exosomes: Composition, biogenesis and function. Nat. Rev. Immunol. 2002, 2, 569-579. [CrossRef]

30. Cunnane, E.M.; Weinbaum, J.S.; O'Brien, F.J.; Dorp, D.A. Future perspective on the role of stem cells and extracellular vesicles in vascular tissue regeneration. Front. Cardiovasc. Med. 2018, 5, 86. [CrossRef]

31. Koniusz, S.; Andrzejewska, A.; Muraca, M.; Srivastava, A.K.; Janowski, M.; Lukomska, B. Extracellular vesicles in physiology, pathology, and therapy of the immune and central nervous system, with focus on extracellular vesicles derived from mesenchymal stem cells as therapeutic tools. Front. Cell. Neurosci. 2016, 10, 109. [CrossRef]

32. Corso, G.; Mager, I.; Lee, Y.; Gorgens, A.; Bultema, J.; Giebel, B.; Wood, M.J.A.; Nordin, J.Z.; El Andaloussi, S. Reproducible and scalable purification of extracellular vesicles using combined bind-elute and size exclusion chromatography. Sci. Rep. 2017, 7, 11561. [CrossRef] [PubMed]

33. Zhang, B.; Yeo, R.W.Y.; Lai, R.C.; Sim, E.W.K.; Chin, K.C.; Lim, S.K. Mesenchymal stromal cell exosome-enhanced regulatory T-cell production through an antigen-presenting cell-mediated pathway. Cytotherapy 2018, 20, 687-696. [CrossRef] [PubMed]

34. Shin, K.O.; Ha, D.H.; Kim, J.O.; Crumrine, D.A.; Meyer, J.M.; Kim, H.K.; Lee, J.; Kwon, H.H.; Park, G.H.; Lee, J.H.; et al. Exosomes from human adipose tissue-derived mesenchymal stem cells promote epidermal barrier repair by inducing de novo synthesis of ceramides in atopic dermatitis. Cells. under review.

35. Wiklander, O.P.B.; Bostancioglue, R.B.; Welsh, J.A.; Zickler, A.M.; Murke, F.; Corso, G.; Felldin, U.; Hagery, D.W.; Evertsson, B.; Liang, X.M.; et al. Systemic methodological evaluation of a multiplex bead-based flow cytometry assay for detection of extracellular vesicle surface signatures. Front. Immunol. 2018, 9, 1326. [CrossRef]

36. Ren, K. Exosomes in perspective: A potential surrogate for stem cell therapy. Odontology 2019, 107, $271-284$. [CrossRef]

37. Yin, K.; Wang, S.; Zhao, R.C. Exosomes from mesenchymal stem/stromal cells: A new therapeutic paradigm. Biomark. Res. 2019, 7, 8. [CrossRef]

38. Kang, K.; Ma, R.; Cai, W.; Huang, W.; Paul, C.; Liang, J.; Wang, Y.; Zhao, Y.; Kim, H.W.; Xu, M.; et al. Exosomes secreted from CXCR4 overexpressing mesenchymal stem cells promote Cardioprotection via Akt signaling pathway following myocardial infarction. Stem Cells Int. 2015, 2015, 659890. [CrossRef]

39. Tan, C.Y.; Lai, R.C.; Wong, W.; Dan, Y.Y.; Lim, S.K.; Ho, K.K. Mesenchymal stem cell-derived exosomes promote hepatic regeneration in drug-induced liver injury models. Stem Cell Res. Ther. 2014, 5, 76. [CrossRef] 
40. Grange, C.; Iampietro, C.; Bussolati, B. Stem cell extracellular vesicles and kidney injury. Stem Cell Investig. 2017, 4, 90. [CrossRef]

41. Cho, B.S.; Kim, J.O.; Ha, D.H.; Yi, Y.W. Exosomes derived from human adipose tissue-derived mesenchymal stem cells alleviate atopic dermatitis. Stem Cell Res. Ther. 2018, 9, 187. [CrossRef]

42. Boltze, J.; Arnold, A.; Walczak, P.; Jolkkonen, J.; Cui, L.; Wagner, D.C. The dark side of the force-Constraints and complications of cell therapies for stroke. Front. Neurol. 2015, 6, 155. [CrossRef] [PubMed]

43. Lou, G.; Chen, Z.; Zheng, M.; Liu, Y. Mesenchymal stem cell-derived exosomes as a new therapeutic strategy for liver diseases. Exp. Mol. Med. 2017, 49, e346. [CrossRef] [PubMed]

44. Ha, D.H.; Kim, S.D.; Cho, B.S.; Lee, J.; Lee, J.H.; Park, S.R.; Youn, J.; Lee, S.H.; Kim, J.E.; Lim, J.; et al. Toxicological evaluation of exosomes derived from human adipose tissue-derived mesenchymal stem/stromal cells. Regul. Toxicol. Pharm.. under review.

45. Mendt, M.; Kamerakar, S.; Sugimoto, H.; McAndrews, K.M.; Wu, C.C.; Gagea, M.; Yang, S.; Blanko, E.V.R.; Peng, Q.; Ma, X.; et al. Generation and testing of clinical-grade exosomes for pancreatic cancer. JCI Insight 2018, 3, e99263. [CrossRef]

46. Zhu, X.; Badawi, M.; Pomeroy, S.; Sutaria, D.S.; Xie, Z.; Baek, A.; Jiang, J.; Elgamal, O.A.; Mo, X.; La Perle, K.; et al. Comprehensive toxicity and immunogenicity studies reveal minimal effects in mice following sustained dosing of extracellular vesicels derived from HEK293T cells. J. Extracell. Vesicles 2017, 6, 1324730. [CrossRef]

47. Saleh, A.F.; Lazaro-Ibanez, E.; Forsgard, M.A.; Shatnyeva, O.; Osteikoetxea, X.; Karlsson, F.; Heath, N.; Ingelsten, M.; Rose, J.; Harris, J.; et al. Extracellular vesicles induce minimal hepatotoxicity and immunogenicity. Nanoscale 2019, 11, 6990-7001. [CrossRef]

48. Maji, S.; Yan, I.K.; Parasramka, M.; Mohankumar, S.; Matsuda, A.; Patel, T. In vitro toxicology studies of extracellular vesicles. J. Appl. Toxicol. 2017, 37, 310-318. [CrossRef]

49. Lobb, R.J.; Becker, M.; Wen, S.W.; Wong, C.S.; Wiegmans, A.P.; Leimgruber, A.; Moller, A. Optimized exosome isolation protocol for cell culture supernatant and human plasma. J. Extracell. Vesicles 2015, 4, 27031. [CrossRef]

50. Gimona, M.; Pachler, K.; Laner-Plamberger, S.; Schallmoser, K.; Rohde, E. Manufacturing of human extracellular vesicle-based therapeutics for clinical use. Int. J. Mol. Sci. 2017, 18, 1190. [CrossRef]

51. Reiner, A.; Witwer, K.W.; van Balkom, B.W.M.; de Beer, J.; Brondie, C.; Corteling, R.L.; Gabrielsson, S.; Gimona, M.; Ibrahim, A.G.; de Kleijn, D.; et al. Concise review: Developing best-practice models for the therapeutic use of extracellular vesicles. Stem Cells Transl. Med. 2017, 6, 1730-1739. [CrossRef]

52. Cheyuo, C.; Aziz, M.; Wang, P. Neurogenesis in neurodegenerative diseases: Role of MFG-E8. Front. Neurosci. 2019, 13, 569. [CrossRef] [PubMed]

53. Shelke, G.V.; Yin, Y.; Jang, S.C.; Lasser, C.; Wennmalm, S.; Hoffmann, H.J.; Li, L.; Gho, Y.S.; Nilsson, J.A.; Lotvall, J. Endosomal signalling via exosome surface TGF $\beta-1$. J. Extracell. Vesicles 2019, 8, 1650458. [CrossRef]

54. Lotvall, J.; Hill, A.F.; Hochberg, F.; Buzas, E.I.; Di Vizio, D.; Gardiner, C.; Gho, Y.S.; Kurochkin, I.V.; Mathivanan, S.; Quesenberry, P.; et al. Minimal experimental requirements for definition of extracellular vesicles and their functions: A position statement from the International Society for Extracellular Vesicles. J. Extracell. Vesicles 2014, 3, 26913. [CrossRef] [PubMed]

55. Witwer, K.W.; Soekmadji, C.; Hill, A.F.; Wauben, M.H.; Buzas, E.I.; Di Vizio, D.; Falcon-Perez, J.M.; Gardiner, C.; Hochberg, F.; Kurochkin, I.V.; et al. Updating the minimal requirements for extracellular vesicle studies: Building bridges to reproducibility. J. Extracell. Vesicles 2017, 6, 1396823. [CrossRef] [PubMed]

56. Andriolo, G.; Provasi, E.; Lo Cicero, V.; Brambilla, A.; Soncin, S.; Torre, T.; Milano, G.; Biemmi, V.; Vassalli, G.; Turchetto, L.; et al. Exosomes from human cardiac progenitor cells for therapeutic applications: Development of a GMP-grade manufacturing method. Front. Physiol. 2018, 9, 1169. [CrossRef] [PubMed]

57. Bari, E.; Perteghella, S.; Di Silvestre, D.; Sorlini, M.; Catenacci, L.; Sorrenti, M.; Marrubini, G.; Rossi, R.; Tripodo, G.; Mauri, P.; et al. Pilot production of mesenchymal stem/stromal freeze-dried secretome for cell-free regenerative nanomedicine: A validated GMP-compliant process. Cells 2018, 7, 190. [CrossRef]

58. Bari, E.; Perteghella, S.; Catenacci, L.; Sorlini, M.; Croce, S.; Mantelli, M.; Avanzini, M.A.; Sorrenti, M.; Torre, M.L. Freeze-dried and GMP-compliant pharmaceuticals containing exosomes for acellular mesenchymal stromal cell immunomodulant therapy. Nanomedicine 2019, 14, 753-765. [CrossRef]

59. Navabi, H.; Croston, D.; Hobot, J.; Clayton, A.; Zitvogel, L.; Jasani, B.; Bailey-Wood, R.; Wilson, K.; Tabi, Z.; Mason, M.D.; et al. Preparation of human ovarian cancer ascites-derived exosomes for a clinical trial. Blood Cells Mol. Dis. 2005, 35, 149-152. [CrossRef] 
60. Pachler, K.; Lener, T.; Streif, D.; Dunai, Z.A.; Desgeorges, A.; Feichtner, M.; Oller, M.; Schallmoser, K.; Rohde, E.; Gimona, M. A good manufacturing practice-grade standard protocol for exclusively human mesenchymal stromal cell-derived extracellular vesicles. Cytotherapy 2017, 19, 458-472. [CrossRef]

61. Rohde, E.; Pachler, K.; Gimona, M. Manufacturing and characterization of extracellular vesicles from umbilical cord-derived mesenchymal stromal cells for clinical testing. Cytotherapy 2019, 21, 581-592. [CrossRef]

62. Roy, S.; Hochberg, F.H.; Jones, P.S. Extracellular vesicles: The growth as diagnostics and therapeutics; a survey. J. Extracell. Vesicles 2018, 7, 1438720. [CrossRef] [PubMed]

63. Cassidy, P.J.; Radda, G.K. Molecular imaging perspectives. J. R. Soc. Interface 2005, 2, 133-144. [CrossRef] [PubMed]

64. Youn, H.; Hong, K.J. In vivo non invasive molecular imaging for immune cell tracking in small animals. Immune Netw. 2012, 12, 223-229. [CrossRef] [PubMed]

65. Gangadaran, P.; Hong, C.M.; Oh, J.M.; Rajendran, R.L.; Kalimuthu, S.; Son, S.H.; Gopal, A.; Zhu, L.; Baek, S.H.; Jeong, S.Y.; et al. In vivo non-invasive imaging of radio-labeled exosome-mimetics derived from red blood cells in mice. Front. Pharmacol. 2018, 9, 817. [CrossRef]

66. Royo, F.; Cossio, U.; de Angulo, A.R.; Llop, J.; Falcon-Perez, J.M. Modification of the glycosylation of extracellular vesicles alters their biodistribution in mice. Nanoscale 2019, 11, 1531. [CrossRef]

67. Gangadaran, P.; Li, X.J.; Lee, H.W.; Oh, J.M.; Kalimuthu, S.; Rajendran, R.L.; Son, S.H.; Baek, S.H.; Signh, T.D.; Zhu, L.; et al. A new bioluminescent reporter system to study the biodistribution of systematically injected tumor-derived bioluminescent extracellular vesicles in mice. Oncotarget 2017, 8, 109894-109914. [CrossRef]

68. Wiklander, O.P.B.; Nordin, J.Z.; O’Loughlin, A.; Gustafsson, Y.; Corso, G.; Mäger, I.; Vader, P.; Lee, Y.; Sork, H.; Seow, Y.; et al. Extracellular vesicle in vivo biodistribution is determined by cell source, route of administration and targeting. J. Extcell. Vesicles 2015, 4, 26316. [CrossRef]

69. Corso, G.; Heusermann, W.; Trojer, D.; Gorgens, A.; Steib, E.; Voshol, J.; Graff, A.; Genoud, C.; Lee, Y.; Hean, J.; et al. Systemic characterization of extracellular vesicle sorting domains and quantification at the single molecule-Single vesicle level by fluorescent correlation spectroscopy and single particle imaging. J. Extracell. Vesicles 2019, 8, 1663043. [CrossRef]

70. Nagyova, M.; Slovinska, L.; Blasko, J.; Grulova, I.; Kuricova, M.; Cigankova, V.; Harvanova, D.; Cizkova, D. A comparative study of PKH67, Dil, and BrdU labeling techniques for tracing rat mesenchymal stem cells. In Vitro Cell. Dev. Biol. Anim. 2014, 50, 656-663. [CrossRef]

71. Horan, P.K.; Slezak, S.E. Stable cell membrane labeling. Nature 1989, 340, 167-168. [CrossRef]

72. Kuffler, D.P. Long-term survival and sprouting in culture by motoneurons isolated from the spinal cord of adult frogs. J. Comp. Neurol. 1990, 302, 72-738. [CrossRef]

73. Morales-Kastresana, A.; Telford, B.; Musich, T.A.; McKinnon, K.; Clayborne, C.; Braig, Z.; Rosner, A.; Demberg, T.; Watson, D.C.; Karpova, T.S.; et al. Labeling extracellular vesicles for nanoscale flow cytometry. Sci. Rep. 2017, 7, 1878. [CrossRef]

74. Lee, T.S.; Kim, Y.; Zhang, W.; Song, I.H.; Tung, C.H. Facile metabolic glycan labeling strategy for exosome tracking. Biochim. Biophys. Acta Gen. Subj. 2018, 1862, 1091-1100. [CrossRef] [PubMed]

75. Jung, K.O.; Jo, H.; Yu, J.H.; Gambhir, S.S.; Pratx, G. Development and MPI tracking of novel hypoxia-targeted theranostic exosomes. Biomaterials 2018, 177, 139-148. [CrossRef] [PubMed]

76. Lee, H.; Park, H.; Noh, G.J.; Lee, E.S. pH-responsive hyaluronate-anchored extracellular vesicles to promote tumor-targeted drug delivery. Carbohydr. Polym. 2018, 202, 323-333. [CrossRef] [PubMed]

77. Goh, W.J.; Zou, S.; Ong, W.; Torta, F.; Alexandra, A.F.; Schiffelers, R.M.; Storm, G.; Wang, J.W.; Czarny, B.; Pastorin, G. Bioinspired cell-derived nanovesicles versus exosomes as drug delivery systems: A cost-effective alternative. Sci. Rep. 2017, 7, 14322. [CrossRef]

78. Choi, H.I.; Choi, J.P.; Seo, J.; Kim, B.J.; Rho, M.; Han, J.K.; Kim, J.G. Helicobacter pylori-derived extracellular vesicles increased in the gastric juices of gastric adenocarcinoma patients and induced inflammation mainly via specific targeting of gastric epithelial cells. Exp. Mol. Med. 2017, 49, e330. [CrossRef]

79. Jang, S.C.; Kim, S.R.; Yoon, Y.J.; Park, K.S.; Kim, J.H.; Lee, J.; Kim, O.Y.; Choi, E.J.; Kim, D.K.; Choi, D.S.; et al. In vivo kinetic biodistribution of nano-sized outer membrane vesicles derived from bacteria. Small 2015, 11, 456-461. [CrossRef] 
80. Faruqu, F.N.; Wang, J.T.W.; Xu, L.; McNickle, L.; Chong, E.M.Y.; Walters, A.; Gurney, M.; Clayton, A.; Smyth, L.A.; Hider, R.; et al. Membrane radiolabeling of exosomes for comparative biodistribution analysis in immunocompetent and immunodeficient mice-A novel and universal approach. Theranostics 2019, 9, 1666-1682. [CrossRef]

81. Rashid, M.H.; Borin, T.F.; Ara, R.; Angara, K.; Cai, J.; Achyut, B.R.; Liu, Y.; Arbab, A.S. Differential in vivo biodistribution of 131I-labeled exosomes from diverse cellular origins and its implication for theranostic application. Nanomedicine 2019, 21, 102072. [CrossRef]

82. Varga, Z.; Gyurkó, I.; Pálóczi, K.; Buzás, E.I.; Horváth, I.; Hegedûs, N.; Máthé, D.; Szigeti, K. Radiolableling of extracellular vesicles with $99 \mathrm{mTc}$ for quantitative in vivo imaging studies. Cancer Biother. Radiopharm. 2016, 31, 168-173. [CrossRef] [PubMed]

83. Hikita, T.; Miyata, M.; Watanabe, R.; Oneyama, C. Sensitive and rapid quantification of exosomes by fusing luciferase to exosome marker proteins. Sci. Rep. 2018, 8, 14035. [CrossRef] [PubMed]

84. Lai, C.P.; Mardini, O.; Ericsson, M.; Prabhakar, S.; Maguire, C.A.; Chen, J.W.; Tannous, B.A.; Breakefield, X.O. Dynamic biodistribution of extracellular vesicles in vivo using a multimodal imaging reporter. ACS Nano 2014, 8, 483-494. [CrossRef] [PubMed]

85. Takahashi, Y.; Nishikawa, M.; Shinotsuka, H.; Matsui, Y.; Ohara, S.; Imai, T.; Takakura, Y. Visualization and in vivo tracking of the exosomes of murine melanoma B16-BL6 in mice after intravenous injection. J. Biotechnol. 2013, 165, 77-84. [CrossRef]

86. Abello, J.; Nguyen, T.D.T.; Marasini, R.; Aryal, S.; Weiss, M.L. Biodistribution of gadolinium- and near infrared-labeled human umbilical cord mesenchymal stromal cell-derived exosomes in tumor bearing mice. Theranostics 2019, 9, 2325-2345. [CrossRef]

87. Banfai, K.; Garai, K.; Ernszt, D.; Pongracz, J.E.; Kvell, K. Transgenic exosomes for thymus regeneration. Front. Immunol. 2019, 10, 862. [CrossRef] [PubMed]

88. Marazioti, A.; Papadia, K.; Kannavou, M.; Spella, M.; Basta, A.; de Lastic, A.L.; Mouzaki, R.A.; Samiotaki, M.; Panayotou, G.; Stathopoulos, G.T.; et al. Cellular vesicles: New insights in engineering methods, interaction with cells and potential for brain targeting. J. Pharmacol. Exp. Ther. 2019, 370, 772-785. [CrossRef]

89. Gao, X.; Ran, N.; Dong, X.; Zuo, B.; Yang, R.; Zhuo, Q.; Moulton, H.M.; Seow, Y.; Yin, H. Anchor peptide captures, targets, and loads exosomes of diverse origins for diagnostics and therapy. Sci. Transl. Med. 2018, 10, eaat0195. [CrossRef]

90. Naseri, Z.; Oskuee, R.K.; Jaafari, M.R.; Moghadam, M.F. Exosome-mediated delivery of functionally active miRNA-142-3p inhibitor reduces tumorigenicity of breast cancer in vitro and in vivo. Int. J. Nanomed. 2018, 13, 7727-7747. [CrossRef]

91. Viñas, J.L.; Spence, M.; Gutsol, A.; Knoll, W.; Burger, D.; Zimplelmann, J.; Allan, D.S.; Burns, K.D. Receptor-ligand interaction mediates targeting of endothelial colony forming cell-derived exosomes to the kidney after ischemic injury. Sci. Rep. 2018, 8, 16320. [CrossRef]

92. Wen, S.W.; Sceneay, J.; Lima, L.G.; Wong, C.S.F.; Becker, M.; Krumeich, S.; Lobb, R.J.; Castillo, V.; Wong, K.N.; Ellis, S.; et al. The biodistribution and immune suppressive effects of breast cancer-derived exosomes. Cancer Res. 2016, 76, 6816-6827. [CrossRef] [PubMed]

93. Nordin, J.Z.; Lee, Y.; Vader, P.; Mäger, I.; Johansson, H.J.; Heusermann, W.; Wiklander, O.P.B.; Hällbrink, M.; Seow, Y.; Bultema, J.J.; et al. Ultrafiltration with size-exclusion liquid chromatography for high yield isolation of extracellular vesicles preserving intact biophysical and functional properties. Nanomedicine 2015, 11, 879-883. [CrossRef] [PubMed]

94. Wang, J.; Hendrix, A.; Hernot, S.; Lemarire, M.; Bruyne, E.D.; Valckenborgh, E.V.; Lahoutte, T.; Wever, O.D.; Vanderkerken, K.; Menu, E. Bone marrow stromal cell-derived exosomes as communicators in drug resistance in multiple myeloma cells. Blood 2014, 124, 555-566. [CrossRef] [PubMed]

95. Grange, C.; Tapparo, M.; Bruno, S.; Chatterjee, D.; Quesenberry, P.J.; Tetta, C.; Camussi, G. Biodistribution of mesenchymal stem cell-derived extracellular vesicles in a model of acute kidney injury monitored by optical imaging. Int. J. Mol. Med. 2014, 33, 1055-1063. [CrossRef] [PubMed]

96. Betzer, O.; Perets, N.; Angel, A.; Motiei, M.; Sadan, T.; Yadid, G.; Offen, D.; Popovtzer, R. In vivo neuroimaging of exosomes using gold nanoparticles. ASC Nano 2017, 11, 10883-10893. [CrossRef] [PubMed]

97. Hwang, D.W.; Choi, H.; Jang, S.C.; Yoo, M.Y.; Park, J.Y.; Choi, N.A.; Oh, H.J.; Ha, S.; Lee, Y.S.; Jeong, J.M.; et al. Noninvasive imaging of radiolabeled exosome-mimetic nanovesicle using 99mTc-HMPAO. Sci. Rep. 2015, 5, 15636. [CrossRef] [PubMed] 
98. Zhang, X.; Bloch, S.; Akers, W.; Achilefu, S. Near-infrared molecular probes for in vivo imaging. Curr. Protoc. Cytom. 2012, 60, 12-27.

99. Boddington, S.; Henning, T.D.; Sutton, E.J.; Daldrup-Link, H.E. Labeling stem cells with fluorescent dyes for non-invasive detection with optical imaging. J. Vis. Exp. 2008, 2, 686. [CrossRef]

100. Yu, G.; Jung, H.; Mok, H. Idocayanine green-incorporated exosomes for improved in vivo imaging of sentinel lymph node. Appl. Biol. Chem. 2016, 59, 71-76. [CrossRef]

101. Verweij, F.J.; Hyenne, V.; Van Niel, G.; Goetz, J.G. Extracellular vesicles: Catching the light in zebrafish. Trands Cell. Biol. 2019, 29, 770-776. [CrossRef]

102. Murphy, D.E.; de Jong, O.G.; Brouwer, M.; Wood, M.J.; Lavieu, G.; Schiffelers, R.M.; Vader, P. Extracellular vesicle-based therapeutics: Natural versus engineered targeting and trafficking. Exp. Mol. Ther. 2019, 51, 32. [CrossRef] [PubMed]

103. Hoshino, A.; Costa-Silva, B.; Shen, T.L.; Rodrigues, G.; Hashimoto, A.; Tesic Mark, M.; Molina, H.; Kohsaka, S.; Di Giannatale, A.; Ceder, S.; et al. Tumor exosome integrins determine organotropic metastasis. Nature 2015, 527, 329-335. [CrossRef] [PubMed]

104. Zhang, L.; Wrana, J.L. The emerging role of exosomes in Wnt secretion and transport. Curr. Opin. Genet. Dev. 2014, 27, 14-19. [CrossRef] [PubMed]

105. Lourenco, S.; Teixeira, V.H.; Kalber, T.; Jose, R.J.; Floto, R.A.; Janes, S.M. Macrophage migration inhibitory factor-CXCR4 is the dominant chemotaxic axis in human mesenchymal stem cell recruitment to tumors. J. Immunol. 2015, 194, 3463-3474. [CrossRef]

106. Garofalo, M.; Villa, A.; Crescenti, D.; Marzagalli, M.; Kuryk, L.; Limonta, P.; Mazzaferro, V.; Ciana, P. Heterologous and cross-species tropism of cancer-derived extracellular vesicles. Theranostics 2019, 9, 5681-5693. [CrossRef]

107. Yun, C.W.; Lee, S.H. Potential and therapeutic efficacy of cell-based therapy using mesenchymal stem cells for acute/chronic kidney disease. Int. J. Mol. Sci. 2019, 20, 1619. [CrossRef]

108. Lv, L.L.; Wu, W.J.; Feng, Y.; Li, Z.L.; Tang, T.T.; Liu, B.C. Therapeutic application of extracellular vesicles in kidney disease: Promises and challenges. J. Cell. Mol. Med. 2018, 22, 728-737. [CrossRef]

109. Herrera, M.B.; Bussolati, B.; Bruno, S.; Morando, L.; Mauriello-Romanazzi, G.; Sanavio, F.; Stamenkovic, I.; Biancore, L.; Camussi, G. Exogenous mesenchymal stem cells localize to the kidney by means of CD44 following acute tubular injury. Kidney Int. 2007, 72, 430-441. [CrossRef]

110. Ullar, M.; Liu, D.D.; Thakor, A.S. Mesenchymal stromal cell homing: Mechanisms and strategies for improvement. iScience 2019, 15, 421-438.

111. Antes, T.J.; Middleton, R.C.; Luther, K.M.; Ijichi, T.; Peck, K.A.; Liu, W.J.; Valle, J.; Echavez, A.K.; Marban, E. Targeting extracellular vesicles to injured tissue using membrane cloaking and surface display. J. Nanotechnol. 2018, 16, 61. [CrossRef]

112. Tian, T.; Zhang, H.X.; He, C.P.; Fan, S.; Zhu, Y.L.; Qi, C.; Huang, N.P.; Xiao, Z.D.; Lu, Z.H.; Tannous, B.A.; et al. Surface functionalized exosomes as targeted drug delivery vehicles for cerebral ischemia therapy. Biomaterials 2018, 150, 137-149. [CrossRef] [PubMed]

113. Kooijmans, S.A.; Aleza, C.G.; Roffler, S.R.; van Solinge, W.W.; Vader, P.; Schiffelers, R.M. Display of GPI-anchored anti-EGFR nanobodies on extracellular vesicles promotes tumor cell targeting. J. Extracell. Vesicles 2016, 5, 31053. [CrossRef] [PubMed]

114. Fais, S.; O’Driscoll, L.; Borras, F.E.; Buzas, E.; Camussi, G.; Cappello, F.; Carvalho, J.; Cordeiro da Silva, A.; Del Portillo, H.; El Andaloussi, S.; et al. Evidence-based clinical use of nanoscale extracellular vesicles in nanomedicine. ASC Nano 2016, 10, 3886-3899. [CrossRef] [PubMed]

115. Fais, S.; Logozzi, M.; Lugini, L.; Federici, C.; Azzarito, T.; Zarovni, N.; Chiesi, A. Exosomes: The ideal nanovectors for biodelivery. Biol. Chem. 2013, 394, 1-15. [CrossRef] [PubMed]

116. Garofalo, M.; Villa, A.; Rizzi, N.; Kuryk, L.; Rinner, B.; Cerullo, V.; Yliperttula, M.; Mazzaferro, V.; Ciana, P. Extracellular vesicles enhance the targeted delivery of immunogenic oncolytic adenovirus and paclitaxel in immunocompetent mice. J. Control. Release 2019, 294, 1650175. [CrossRef]

117. Schindler, C.; Collinson, A.; Mattews, C.; Pointon, A.; Jenkinson, L.; Minter, R.R.; Vaughan, T.; Tigue, N.J. Exosomal delivery of doxorubicin enables rapid cell entry and enhanced in vitro potency. PLoS ONE 2019, 14, e021454. [CrossRef] 
118. Ran, L.; Tan, X.; Li, Y.; Zhang, H.; Ma, R.; Ji, T.; Dong, W.; Tong, T.; Liu, Y.; Chen, D.; et al. Delivery of oncolytic adenovirus into the nucleus of tumorigenic cells by tumor microparticles for virotherapy. Biomaterials 2016, 89, 55-66. [CrossRef]

119. Garofalo, M.; Villa, A.; Rizzi, N.; Kyryk, L.; Mazzaferro, V.; Ciana, P. Systemic administration and targeted delivery of immunogenic oncolytic adenovirus encapsulated in extracellular vesicles for cancer therapies. Viruses 2018, 10, 558. [CrossRef] 